\title{
Proposal of a lumped hydrological model based on general equations of growth - application to five watersheds in the UK
}

\author{
C. Prieto Sierra ${ }^{1}$, E. García Alonso ${ }^{2}$, R. Mínguez Solana ${ }^{1}$, and \\ R. Medina Santamaría ${ }^{1}$ \\ ${ }^{1}$ Environmental Hydraulics Institute, "IH Cantabria", Santander, Spain \\ ${ }^{2}$ Independent Consultant in Water Engineering, Santander, Spain \\ Received: 28 June 2013 - Accepted: 3 July 2013 - Published: 17 July 2013 \\ Correspondence to: C. Prieto Sierra (prietoc@unican.es) \\ Published by Copernicus Publications on behalf of the European Geosciences Union.
}

\begin{abstract}
This paper explores a new approach to lumped hydrological modelling based on general laws of growth, in particular using the classic logistic equation proposed by Verhulst. By identifying homologies between the growth of a generic system and the evo5 lution of the flow at the outlet of a river basin, and adopting some complementary hypotheses, a compact model with 3 parameters, extensible to 4 or 5 , is obtained. The model assumes that a hydrological system, under persistent conditions of precipitation, potential evapotranspiration and land uses, tends to reach an equilibrium discharge that can be expressed as a function of a dynamic aridity index, including a free parameter 10 reflecting the basin properties. The rate at which the system approaches such equilibrium discharge, which is constantly changing and generally not attainable, is another parameter of the model; finally, a time lag is introduced to reflect a characteristic delay between the input (precipitation) and output (discharge) in the system behaviour. To test the suitability of the proposed model, 5 previously studied river basins in the

15 UK, with different characteristics, have been analysed at a daily scale, and the results compared with those of the model IHACRES (Identification of unit Hydrographs and Component flows from Rainfall, Evaporation and Streamflow data). It is found that the logistic equilibrium model with 3 parameters properly reproduces the hydrological behaviour of such basins, improving the IHACRES in four of them; moreover, the model

20 parameters are relatively stable over different periods of calibration and evaluation. Adding more parameters to the basic structure, the fits only improve slightly in some of the analysed series, but potentially increasing equifinality effects. The results obtained indicate that growth equations, with possible variations, can be useful and parsimonious tools for hydrological modelling, at least in certain types of watersheds.
\end{abstract}




\section{Introduction}

Nowadays hydrological models are widely used tools for various purposes, among which the following can be highlighted: to extend the series of flows in ungauged watersheds (e.g. Sefton and Howarth, 1998); to evaluate management strategies (e.g. Gar-

5 cía et al., 2008); to evaluate the response of watershed in different types of climate (e.g. Jakeman et al., 1993); to predict future flows (e.g. Beven, 2012a); to design flood protections works (e.g. Lamb, 1999); to evaluate water quality (e.g. Mroczkowski et al., 1997); to analyse the impact of climate change (e.g. Sefton and Boorman, 1997); to assess ecological parameters and characterize habitats (e.g. Singh and Woolhiser, 10 2002), etc.

Its origins date back to the 19th-century, with the well-known rational method proposed by Mulvany (cited by Todini, 2007), and since the 1960s there has been a proliferation of different types of hydrological models. According to the classification proposed by Wheater et al. (1993), models can be grouped in three categories: models

15 based on data, or black box; conceptual parametric models based on storages, or grey box; and models based on physical processes, or white box.

In 2004, Wagener et al. extended the definition given by Wheater et al. (1993) to conceptual models, characterizing them as those whose structure is determined prior to modelling, without having to necessarily make use of storages, and having typically at

20 least some of their parameters obtained by means of calibration through observations. The model proposed in this paper belongs to this last group of models.

The majority of hydrological models used to estimate flows in catchments with scarce available data are conceptual lumped type models; in such circumstances, this type of models performs as well as those based on physical processes (Littlewood, 2002b),

25 which require a lot of data which may be generally unavailable (hydro-meteorological, soil, vegetation and land use), and are of great complexity (Sefton and Howarth, 1998; Littlewood, 2001; Beven, 2002; Perrin et al., 2003).

9311

In watersheds where there are no discharge measurements, it becomes difficult to apply any kind of model, even of the conceptual type. To address this problem, techniques have been developed for regionalization, which consists in calibrating hydrologic models in river basins where measurements are available, finding statistical or physical 5 relationships that link the parameters with characteristics of the watersheds, and using these relationships to extrapolate to ungauged basins (Littlewood, 2003; Silvapalan et al., 2003). However, the prediction of flows in watersheds without instrumentation remains an issue still not satisfactorily and completely resolved (Wagener and Montanari, 2011).

10 In most hydrological models, the goodness-of-fit provided by multiple combinations of parameters is often similar, in terms of an objective function (hereafter OF), which results in a range of plausible predictions, without there being a specific set of parameters that can be regarded as optimal (Beven, 2012a). According to Gupta et al. (1998), the structure of the model is an imperfect representation of reality and the problem is

15 inherently multiobjective. That it is to say, different sets of parameters adjust different aspects of the hydrograph, giving a set of Pareto solutions, a range in which all the possible responses of the basin will lie. The problem of the formulation and determination of the correct structure of a model is thus one of the major challenges of hydrology.

This article will explore the potential of general equations of growth (Wallance and

20 Tsoularis, 2002), as a basis for the construction of a conceptual parsimonious hydrological model (see Savenije, 2009). Section 2 looks briefly at the current State of the Art of conceptual models, different methods of calibration in hydrology, and some areas of knowledge where growth equations have been applied. The analogy between these applications and hydrological systems has served as the basis for the proposed new

25 structure, described in Sect. 3. In Sect. 4, the model is applied to 5 previously studied UK basins, with daily data (Littlewood, 2006). To contextualize the results, they will be compared with results obtained using the IHACRES model in these same watersheds (Sefton and Boorman, 1997; Littlewood, 2002b, 2003). Finally, some reflections on the 
properties and limitations of the approach introduced and the main conclusions of the work are presented in Sects. 5 and 6.

\section{State of the art}

\subsection{Description of the general structure of conceptual models}

5 According to Beven (2001), a conceptual model, regardless of its degree of complexity, is a mathematical description of what the hydrologist observes, i.e. of the perceptual model. That is to say, of how a basin responds to precipitation under various conditions. Conceptual models make simplifications of reality, while retaining some representations of the basic physical processes. When they try to represent many sub-

10 processes explicitly, they become very complex structures with many parameters (Littlewood, 2001).

Since the mid-twentieth century, hydrologists have sought to reproduce the processes that occur in hydrological systems using mathematical models. Most of these models have a similar structure, employing a series of storages and using equations o describe the exchanges between them, differing from each other mainly in the number and type of parameters. Almost all of them are able to represent the behaviour of the basins reasonably well, especially in the calibration period, by simply adding more parameters, which often results in a large number of over-parameterized structures.

There have been several studies comparing models of different complexity. In his 20 doctoral thesis, Wagener (2004) highlights a number of general findings common to all of them: in wet conditions, and when there is sufficient data to calibrate, simple structures work as well or better than those with many parameters, although, on a daily scale, it is possible that they do as well only in the calibration but not in the validation, due to the lack of robustness of the parameters. As an advantage, more parsimonious

25 models reduce problems of identification, and a range between 3 and 5 parameters is usually sufficient to represent the daily flows of a basin. It is estimated that the number

9313

of parameters that can be identified from a daily series of precipitation and flow, using a traditional calibration scheme with one OF is 5 or 6 ; in many lumped models, a linear response function, which separates fast and slow flow contributions, is sufficient for continuous daily scale models. A description of some of the lumped type models that 5 are currently in use can be found in Beven (2012a). Thus, for example, in the US it can be highlighted the HSPF, the SSAR and the Sacramento; in Japan, the Tank; in Canada, the UBC; in Australia, the RORB, AWBM and IHACRES; in Sweden, the HBV and its different versions; and in France, the GR4J.

A variant of this class of models are those that are intended to simulate the be10 haviour of the basin on a global scale, but using a function that represents the spatial variability of runoff generation. For example, the PDM (Probability Distributed Moisture; Moore, 2007), which employs a purely statistical distribution function, and the Xinanjiang, ARNO and VIC which use a simple function (Ortiz, 2009).

Most of these models separate the hydrological processes into two parts: one related 15 to the vertical flows, the balance of water masses or the fraction of the precipitation that is converted into runoff (soil moisture accounting or SMA); and the other to the transport of the net precipitation to produce the flow (routing). The first one is generally replicated by a nonlinear function. With respect to the routing, the most common way to describe this process in this type of models is by means of a linear relation-

20 ship, based on the conceptual behaviour of a linear storage (Jakeman and Hornberger, 1993), which is equivalent to a discrete-time first order transfer function (hereinafter TF) (Jakeman et al., 1990; Young, 2011). In addition, the TF can also represent any combination of storages connected in series and/or in parallel (Chow et al., 1988) and its parameters can be estimated with the algorithm SRIV (Jackeman et al., 1990; Young, 25 2011). Nevertheless, the assumption of linear routing is a simplification that is usually adopted to facilitate the separation of the flow components, but the effects of storage and retention basins are generally non-linear (Wittenberg, 1994; Wittenbert and Sivapalan, 1999). Instead of a linear function, some of the mentioned models employ exponential configurations of storages (Herron and Croke, 2009) or a potential form for 
the unit hydrograph (Croke, 2006). Among the previous models, the IHACRES package has been chosen as benchmarking tool of the performance of the new model, and to contextualize the results obtained.

In recent years, under the philosophy that there is no single structure which is suit5 able for all purposes and that its choice is a function of the modeller's objectives, the characteristics of the hydrological system and the available data, several modular systems have been developed. These sets of tools, in addition to allow the combination of different components of models, provide a set of functions to construct, manipulate, analyse and compare hydrological models, thereby resulting in appropriate structures

10 for each application. Two of these software packages are the Rainfall runoff modeling Toolbox of Imperial College (RRMT; Wagener et al., 2004) and the Hydromad (Andrews et al., 2011), which includes IHACRES.

Once a model structure is adopted, the next step is model calibration. Various different approaches have been taken regarding the subject of calibration and the estimation

15 of uncertainty (Beven, 2002; Andrews et al., 2011). Accordingly, there are search methods based on the existence of a single optimal set of parameters, which disregards the estimation of the uncertainty associated with predictions. These range from manual calibration to automatic optimization algorithms. Among the latter, the SCE (Shuffled Complex Evolution), developed at the University of Arizona (Duan et al., 1992) and 20 characterized by its robustness in finding the global optimum from a surface, stands out as one that was explicitly designed for hydrological modeling. Even so, this type of algorithm has not been able to completely replace manual calibration (Boyle et al., 2000). Another group of techniques are those that employ the methods of Bayesian statistics (Beven, 2012a,b), or multi-criteria calibration methods (Gupta et al., 1998; Yapo et al., 25 1998), which makes use of the concept of the "Pareto optimum". The amount of information obtained using one OF is sufficient to identify 3 to 5 parameters, although the majority of the structures of conceptual models contain a larger number (Wagener, 2004). The more parsimonious the model, the smaller the number of processes which can be separately reproduced, and the model may not be realistic outside the specific

$$
9315
$$

conditions for which it was calibrated (Kuczera and Mroczkowski, 1998). Also listed among this type of non-statistical approach to uncertainty is the GLUE (Generalized Likelihood Uncertainty Estimation; Beven, 2012a), that allows for epistemic sources of error, instead of statistical. In relation to the measure of goodness of the model, the 5 structure of these errors will not be stationary, due to the epistemic nature of the residuals, neither in the calibration nor in the prediction; the classical theory of statistical probability measures, based on the analysis of residuals, are consequently little informative. The hypotheses of homoscedasticity and the hypotheses that autocorrelation is negligible are not valid. We must aim at OF that adequately reflect the essence of 10 a particular application (Yapo et al., 1996). In short, after $50 \mathrm{yr}$ of research, the choice of structure and the set of parameters appropriate to a conceptual hydrological model, which reproduce and characterize the response of any watershed, remains a problem not fully resolved within the prevailing paradigm in the hydrological sciences. However, among the wide range of tools that have been developed in the last decades, there is generally at least one which is appropriate for the practical purposes of any specific case.

\subsection{Some applications of growth equations}

Since the beginning of the 19th century, growth equations have been used to represent a great variety of systems. Equations of growth, in the context of this article, refers to

20 a large family of ordinary differential equations (hereafter ODE), in which the variation of a variable $X$ with time $t$ is equal to the product of two algebraic functions: an unbounded growth factor $f_{1}$ and another growth factor $f_{2}$ limited or conditioned by an exogenous variable $X_{\max }$ (Tsoularis and Wallace, 2002):

$$
\frac{\mathrm{d} X}{\mathrm{~d} t}=f_{1}(X) \cdot f_{2}\left(X ; X_{\max }\right) .
$$


The first modern equation of growth can be probably credited to Malthus (1798), who studied the evolution of a population $P(t)$ assuming that it increased by a geometric rate $r$ :

$\frac{\mathrm{d} P(t)}{\mathrm{d} t}=r \cdot P(t)$.

5 Subsequently, Verhulst (1838) labelled this exponential growth as unrealistic, arguing that a stable population would have a level of saturation, characteristic of the environment (carrying capacity K). Verhulst was the first to give an explanation for what is today known as a S-curve, applicable to many natural processes that show a temporal progression from a low level up to a climax. Throughout the 20th century, nu-

10 merous applications of growth curves have been proposed in areas as varied as biology (e.g. Blumberg, 1968), demography (e.g. see Pearl in Tsoularis and Wallace, 2002), ecology (e.g. Bertalanffy, 1938; Richards, 1959; Smith, 1963; Gilpin et al., 1976; Buis, 1991; Zeide, 1993), technology (e.g. Marchetti and Nakicenovic, 1980), marketing (e.g. Fisher and Pry, 1971), etc. Some authors have tried to formulate a general curve 15 that would encompass all of the above (Turner et al., 1976; Heinen, 1999; Tsoularis and Wallance, 2002). Savageau (1980), for example, generalizes a growth equation valid for complex systems, since their behaviour can be linked to the mechanisms of their components and the relationships between them. The previous references restrict to models of growth with a single variable, but some classic models in mathematical

20 biology and ecology, such as the Lotka-Volterra (Lotka, 1925) and the Jacob-Monod (Smith and Waltman, 1997), represent growth laws extended to several variables. What all these applications, in such diverse fields, have in common is that they all represent a gradual variation of a certain quantity over time, governed by a limiting factor and that they can be analyzed from the perspective of the equations of evolution (Carrillo and

25 Gonzalez, 2002). In this paper we will explore the application of this type of equations as the basis for a lumped hydrological model, a field where no previous references of this approach have been found, although the concept of the S-Hydrograph (Chow, 1994) formally resembles a typical growth curve.

9317

\section{Description of the proposed model}

\subsection{Homology between growth models and hydrological systems}

Let us assume a basic hydrological system conformed by a basin that drains into a river section, where the instantaneous or time-averaged discharge is the key output variable.

5 The rainfall-runoff transformation processes will be governed by a series of fixed parameters and by at least two input variables: the precipitation $(P)$ and the potential evapotranspiration (ETP), or a proxy of it as the daily maximum temperature $(T)$. The evolution of the system is equivalent to the variation of the discharge over time which, within the framework of growth equations, is given by the product of an unbounded 10 function and a bounded one, which includes a limiting factor. It is consistent with the observation to assume that a watershed will tend to generate a constant discharge at a control point, if the climatic inputs (precipitation and potential evapotranspiration), land uses and vegetation remain stable over a period sufficiently long. This equilibrium flow, attained when the basin reaches full saturation and stable conditions in all

15 possible runoff pathways (surface, subsurface and groundwater), will tend to a value equal to the difference between precipitation and the equilibrium evapo-transpiration rate (hereafter ET) corresponding to these stable conditions. It is therefore plausible to analyze equations of the type:

$$
\frac{\mathrm{d} Q}{\mathrm{~d} t}=f_{1}(Q) \cdot f_{2}\left(Q ; Q_{\text {eq }}(P, \mathrm{ET})\right)
$$

20 as potential candidates to represent, in an aggregate manner, the hydrological behaviour of a basin. The forms that can be taken by $f_{1}$ and $f_{2}$ are very diverse, as is evident from the literature cited before, and in this article we will focus on the classical logistic equation. The simplest approach to estimate the equilibrium discharge draws on a related concept, which is the equilibrium runoff coefficient $\left(c_{\text {eq }}\right)$, which reflects an 
equilibrium ratio between net and total rainfall. According to this, a general expression for the equilibrium discharge can possibly adopt the following shape:

$Q_{\mathrm{eq}}(t)=P(t) \cdot C_{\mathrm{eq}}(t)$.

A constant value for $c_{\text {eq }}$ could be realistic in places without climatic seasonality, or 5 when the simulation period is short enough to assume stationary conditions but, on a general basis, $c_{\mathrm{eq}}$ will be a function of the previous history of rainfall and potential $\mathrm{ET}$ in the basin. A widely used parameter to characterize the runoff generation potential of a basin is the aridity index $\Phi$, defined as the quotient $\Phi=P E T / P$. This adimensional ratio, when calculated using mean long-term values of $P$ and PET, is well correlated with

10 the mean runoff coefficient, yielding a family of functions often called Budyko curves (Arora, 2002). The Budyko function $F(\Phi)$ links the mean runoff coefficient of a basin with the aridity index in a simple way:

$c=\frac{P-\mathrm{ET}}{P}=1-F(\Phi)$.

Various forms have been proposed for $F(\Phi)$, including those of Schreiber, Ol'dekop,

15 Budyko, Turc, Pike, etc. (Ibid.). It must be noted that these relationships are closed relationships, static in nature, reflecting mean conditions that in theory should apply universally for all basins in all types of climate, if the input records were accurate, sufficiently long and stationary.

In the following section, this conceptual framework will be extended to propose a general expression for the equilibrium runoff coefficient, yielding an expression for the equilibrium discharge. Such discharge is assumed to be equivalent to the carrying capacity of a hydrological system, ready to be plugged into a especific equation of growth (functions $f_{1}$ and $f_{2}$ ) that, as will be proved, has to comply with some other physical restrictions.

\subsection{The logistic equilibrium model}

\subsubsection{Basic structure of the model}

Based on the analogy between the carrying capacity of a watershed and its equilibrium discharge, the most basic limited growth law, the so called logistic or Verhulst equation, 5 will be applied to formulate a conceptual hydrological model. This classical equation has the general form (Tsoularis and Wallace, 2002):

$\frac{\mathrm{d} N}{\mathrm{~d} t}=r \cdot N\left(1-\frac{N}{K}\right)=\frac{r \cdot N}{K} \cdot(K-N)$

where $N$ is the population or any other dependent variable, $K$ is the system saturation constant or carrying capacity, and $r$ a growth rate. In this model, the rate of population 10 increase $\mathrm{d} N / \mathrm{d} t$ is given by the product of a linear function of the existing population $\left(f_{1}\right)$ and another linear function $f_{2}$ that expresses the remaining capacity to achieve full conditions. In the hydrological field, the variable of interest is the averaged discharge $Q$, in a section of river over a time span $\mathrm{dt}$, expressed as a specific discharge, i.e. with velocity units (mm day ${ }^{-1}$ in this work). The carrying capacity $K$ will be renamed in

15 this context as the equilibrium discharge $Q_{\text {eq }}$, defined as the constant flow that would be potentially reached if all the hydrological variables involved in the process (rainfall, evapotranspiration, land uses, etc.) remained constant for long enough. Replacing the newly named variables in the logistic equation, the following expression is obtained:

$\frac{\mathrm{d} Q}{\mathrm{~d} t}=r \cdot Q(t) \cdot\left(1-\frac{Q(t)}{Q_{\mathrm{eq}}(t)}\right)=r \cdot \frac{Q(t)}{Q_{\mathrm{eq}}(t)} \cdot\left(Q_{\mathrm{eq}}(t)-Q(t)\right)$.

20 However, Eq. (7) is not a valid hydrological model, because when $Q_{\mathrm{eq}}(t)=0$, a situation that occurs during dry spells, it does not produce a physically valid recession curve of 
the flow, yielding an infinite value for $\mathrm{d} Q / \mathrm{d} t$. In particular, when $Q_{\mathrm{eq}}=0$, the resulting expression should be of the type (Wittenberg and Sivapalan, 1999):

$\frac{\mathrm{d} Q}{\mathrm{~d} t}=-A \cdot Q(t)^{B} ; A>0 ; B>0$.

Particular cases of Eq. (8) occur if $B$ is equal to 1 (exponential recession curve) or if

$5 B$ is equal to 2 (hyperbolic recession curve). It is immediately apparent that for Eq. (8) to take the form of Eq. (9) with $Q_{\text {eq }}=0$, the growth rate $r$ must be equal to a constant $A$ multiplied by $Q_{\text {eq }}$ :

$r=A \cdot Q_{\mathrm{eq}}(t)$.

In other words, the capacity of the system to increase the discharge has to be time10 varying and proportional to the maximum attainable discharge at each moment. Substituting Eq. (10) in Eq. (8), a modified version of the logistic equation which is a priori applicable to hydrological systems is obtained:

$\frac{\mathrm{d} Q}{\mathrm{~d} t}=A \cdot Q \cdot\left(Q_{\mathrm{eq}}(t)-Q\right)$.

If $Q_{\mathrm{eq}}=0$, this equation becomes a simple recession law with a hyperbolic-type 15 solution:

$\frac{\mathrm{d} Q}{\mathrm{~d} t}=-A \cdot Q^{2}$

Physically, these expressions indicate that the rate of growth of the discharge is proportional to the actual discharge and to the margin remaining until the saturation flow is reached. The parameter $A$ represents the rate of response of the watershed from

20 the instantaneous imbalance imposed by the variations of the equilibrium discharge, has dimensions of the inverse of the length $\left(\mathrm{mm}^{-1}\right.$ in this article), and represents an

9321

equivalent thickness of a conceptual non-linear reservoir. Equation (10) has analytical solution, assuming that $Q_{\mathrm{eq}}(t)$ is constant:

$$
\begin{aligned}
Q(t)=\frac{Q_{0} \cdot Q_{\mathrm{eq}}(t)}{\left(Q_{\mathrm{eq}}(t)-Q_{0}\right) \cdot e^{-\left(A \cdot t \cdot Q_{\mathrm{eq}}(t)\right)}+Q_{0}} & \text { if } Q_{\mathrm{eq}}>0 \\
Q(t)=\frac{Q_{0}}{1+A \cdot Q_{0} \cdot t} & \text { if } Q_{\mathrm{eq}}=0
\end{aligned}
$$

where $Q_{0}$ represents the initial condition. This analytical solution can be used to integrate numerically Eq. (10), as will be showed later. Equations (12) and (13) are the basis of the numerical scheme employed in this work. A variant of the logistic equation that will be tested further on in this paper is to assume that the value of $A$ is different 10 when the discharge is increasing or decreasing ( $\mathrm{d} Q / \mathrm{d} t$ greater or lower than zero); in that case, we will call the two constants $A_{\mathrm{u}}$ (rise), and $A_{\mathrm{d}}$ (descent). While other equations of growth are potentially valid to build hydrological models, in this context we will focus on the application of the logistic equation, and the variant previously mentioned.

\subsubsection{Expression of the equilibrium discharge}

15 While the logistic equation provides the basic structure of the model, it is necessary to obtain an expression for the equilibrium discharge, another key element of the proposed conceptual framework. As has already been discussed, a working hypothesis is to assume an equilibrium discharge expressed as the product of the precipitation and an equilibrium runoff coefficient, which reflects the effect of the antecedent moisture conditions (Eq. 4).

In order to obtain a valid expression for $c_{\text {eq }}$, it is proposed to extend the concept of the Budyko functions based on the aridity index, as introduced in Sect. 3.1. It will be assumed that the equilibrium runoff coefficient depends on an aridity index corresponding to a period of time prior to each moment of calculation, calculated with smoothed 
values of precipitation and PET. When obtaining the aridity index $(\mathrm{PET} / P)$ with averaged values of PET and $P$, which will be called PET* and $P^{*}$, a memory factor $(\lambda)$ is introduced in the system, that can be regarded as a new parameter in the model, or treated as a fixed parameter if it is proved to have little impact on the results. To obtain

5 the averaged $\left(X^{*}\right)$ version of a variable $X$, an exponential smoothing is applied, with a filter length directly proportional to the memory of the system and reflected in the parameter $\lambda$ :

$X^{*}(t)=\lambda \cdot \int_{0}^{\infty} X(t-\xi) \cdot e^{-\lambda \cdot \xi} \cdot d \xi$.

With the smoothed values $\mathrm{PET}^{*}$ and $P^{*}$, it is possible to calculate a dynamic arid10 ity index $\left(\Phi^{*}\right)$ which can be plugged into some of the existing Budyko-type functions. However, these functions are fully fixed and don't have free parameters, since they reflect an average behaviour, a priori universal, of all watersheds, based on long annual series. In the context of a hydrological model, and in order to obtain an equilibrium runoff coefficient, it is proposed to adopt any of the existing functions, keeping their asymptotic properties, but leaving a free parameter which reflects the main features of each particular basin. For instance, from the Turc-Pike's formula, it is straight-forward to build an expression with a free parameter $P_{1}$ :

$$
\frac{\mathrm{ET}}{P}=\frac{1}{\sqrt{1+\left(\frac{P_{1}}{\Phi^{*}}\right)^{2}}}
$$

which yields the following expression for $Q_{\text {eq }}$ :

${ }_{20} Q_{\mathrm{eq}}(t)=P(t) \cdot\left(1-\frac{1}{\sqrt{1+\left(P_{1} \cdot \frac{P^{*}}{\mathrm{PET}^{*}}\right)^{2}}}\right)$

Such an expression for $Q_{\text {eq }}$ enables to take into account the specific features of the basin, through the parameter $P_{1}$, and the previous history of PET and $P$, by introducing a dynamic aridity index with memory effect, through the parameter $\lambda$. The relationship between $\lambda$ and the system memory, expressed as the time $\left(t_{m}\right)$ in which the weight of 5 an antecedent value becomes $37 \%(1 / e)$ of the weight of the present value, is:

$t_{\mathrm{m}}=\frac{1}{\lambda}$

where $t_{\mathrm{m}}$ has the same temporal units as the input data. As will be seen later, the expected values of $\lambda$ are between 20 and 60 days, and for practical purposes, the model tends to be little sensitive to this parameter.

\section{$10 \quad 3.2 .3$ Introduction of a time lag}

The logistic model, as it has been presented, generates an instantaneous response of the basin to the precipitation. This immediacy in the response can be realistic when the ratio between the response time of the watershed and the time step is sufficiently low, but in practice there is usually a lag between the incidence of rain and the associated discharge at the basin outlet. Trying to preserve the parsimony of the model, the most straight-forward way to introduce this time lag is through a delay factor $(\tau)$ between the $Q_{\text {eq }}$ at the point of production and the $Q$ at the measuring point. In physical terms, $\tau$ fulfils the mission to transfer the runoff production over the entire surface of the basin to the point of flow measurement. Strictly, the delay should depend on the current dis20 charge and the spatial structure of the precipitation fields in the basin $\tau=\tau(Q ; f(x, y))$, but these dependencies, which introduce new parameters and require more input data, will not be considered in the basic version of the model, where $\tau$ will be taken as a constant. For practical purposes, $\tau$ represents a new fitting parameter of the model, and 
the final expression for the logistic equilibrium model, including a time delay, has the following shape:

$\frac{\mathrm{d} Q}{\mathrm{~d} t}=A \cdot Q(t) \cdot\left(Q_{\mathrm{eq}}(t-\tau)-Q(t)\right)$

\subsubsection{Numerical solution of the model}

5 The exact solution to the basic logistic equation in Eq. (10) can be used to integrate numerically Eq. (18), assuming that during each time step $Q_{\text {eq }}(t)$ remains constant (zero-order hold solution):

$$
\begin{array}{ll}
Q_{t+1}=\frac{Q_{t} \cdot Q_{\mathrm{eq}, t-\tau}}{\left(Q_{\mathrm{eq}, t-\tau}-Q_{t}\right) \cdot \exp \left(-A \cdot \Delta t \cdot Q_{\mathrm{eq}, t-\tau}\right)+Q_{t}} & \text { if } Q_{\mathrm{eq}, t-\tau}>0 \\
Q_{t+1}=\frac{Q_{t}}{1+A \cdot Q_{t} \cdot \Delta t} & \text { if } Q_{\mathrm{eq}, t-\tau}=0 .
\end{array}
$$

In this work, Eq. (18) has been treated as an ordinary differential equation (ODE), and expressions Eqs. (19) and (20) have been used as a numerical solution of the proposed model; consistently with this approach, the value of $Q_{\mathrm{eq}}(t-\tau)$ has been obtained by linear interpolation between the nearest values of $Q_{\text {eq }}$ corresponding to multiples of $15 \Delta t$.

However, function $Q_{\text {eq }}$ is not a standard, continuous and derivable expression, since the factor $P(t)$ that it contains, entails all the properties of an averaged (temporally and spatially) rain field, including intermittency and fractality. Thus, strictly speaking, the zero-order hold $(\mathrm{ZOH})$ assumption is not valid for Eq. (18) and the delayed term

$20 Q_{\text {eq }}(t-\tau)$ should not be approximated with standard methods of interpolation, devised for smooth functions. Due to the mathematical of $Q_{\text {eq }}(t)$, Eq. (18) should be formally treated as a stochastic delay differential equation (SDDL).

$$
9325
$$

\subsection{Model optimization and objective function}

For given time series of length $n$, associated with flow $Q$, precipitation $P$, and potential evapotranspiration PET, the parameter estimates of the proposed model $\widehat{P}_{1}, \widehat{\tau}$ and $\widehat{A}$ are obtained by solving the following optimization problem:

5 Minimize : $F\left(P_{1}, \tau, A\right)=\frac{1}{2} \cdot\left(\frac{\sum_{t=1}^{n}\left(\widehat{Q}_{t}-Q_{t}\right)^{2}}{\sum_{t=1}^{n}\left(\widehat{Q}_{t}-\bar{Q}\right)^{2}}\right)+\frac{1}{2} \cdot \frac{\sum_{t=1}^{n}\left|\widehat{Q}_{t}-Q_{t}\right|}{\sum_{t=1}^{n} Q_{t}}$.

Subject to constraints Eqs. (16), (19) and (20), where $\widehat{Q}_{t} ; \forall t=1, \ldots, n$, are the discharge estimates from the proposed model. The OF chosen for this application is an equally weighted linear combination between (i) unity minus the Nash-Sutcliffe efficiency coefficient (hereafter NS), i.e. 1-NS, and (ii) the volume difference (bias). This mixed OF tries to reflect a compromise between high and mean values, and has shown good results in the study cases that will be presented later.

Due to the non-linearities associated with the proposed model equations, and the discrete nature of precipitations, the parameter optimization is a non-linear and nonconvex problem. Assuming the existence of upper and lower bounds for each model 15 parameter, which are easily determined through physical considerations, the solution of this parameter estimation problem may be obtained by using any of the existing non-convex, non-linear optimization routines existing in the literature, such as the SCE (Duan et al., 1992). We have, however, used a global optimization method which combines a recursive hyperrectangle (the generalization of a rectangle for higher dimen20 sions defined as the Cartesian product of intervals defined by bounds) Monte Carlo simulation to find starting values for the parameter estimates, and gradient-based nonlinear programming solvers. This method belongs to the multistart family (Törn, 1979) and it uses a local algorithm starting from several points distributed over the whole optimization region. In this particular case, we have used the Trust Region Reflective 
Algorithm under Matlab (Coleman and Li, 1994, 1996), also capable of dealing with nonlinear equality constraints and upper and lower bounds through the function fmincon. This method has proved to be robust and efficient for this particular application.

\section{Results of the model}

5 To evaluate the behaviour of the structure proposed in this paper, we have analysed five basins in the UK at a daily scale, previously fitted with the IHACRES model (Littlewood, 2001, 2002, 2003; Sefton and Boorman, 1997). In order to be able to contextualise the new model, the fits obtained will be compared with the IHACRES results in these watersheds, using the same periods of calibration and evaluation. In all cases, Eq. (21)

10 has been used as OF.

\subsection{River TEIFI in Glan Teifi}

The River Teifi belongs to the basin of the Glan Teifi (Wales) and has been used in various studies (Littlewood, 2001, 2002, 2003). The Teifi River Basin has an area of $894 \mathrm{~km}^{2}$, its source is located at an altitude of 500 ma.s.l. and has an almost natural

15 flow regime. The mechanisms of production of runoff in this basin are dominated by surface and subsurface processes. In the period 1959-1995, annual average values of rainfall and flow drained by the basin were 1355 and $997 \mathrm{~mm}$, respectively. Between 10 January 1980 and 30 October 1990, the average daily flow was $2.82 \mathrm{~mm} \mathrm{day}^{-1}$; the flow that was exceeded 90 and $10 \%$ of the time were of 0.33 and $6.66 \mathrm{~mm} \mathrm{day}^{-1}$, re-

20 spectively. The logistic equilibrium model has been applied to the same intervals and using the same nomenclature as in the works of Littlewood and are presented in Table 1. Also in Table 1, for each calibrated sub-period, are the values of the variance explained by the model (daily NS coefficient), and the best fit parameters $\left(P_{1}, \tau, A\right)$. It must be noted that $\lambda$ has been taken as a constant value equal to 30 days, and its influence will be discussed in a subsequent section. The volume deviation (bias) is not

$$
9327
$$

shown as it is zero in all cases when the mixed OF is applied. As follows from the observations of rows 2 to 12 (the periods used in Littlewood, 2001), during calibration all intervals made a good fit in terms of NS, between 0.905 (\#2) and 0.954 (\#8). With regard to the optimal parameters, Fig. 1 shows both the values of the median, as well 5 as the first and third quartiles. The largest standard deviation about the mean is given by the parameter $P_{1}$, which was $15.66 \%$, while $\tau$ had $9.60 \%$ and $A 5.99 \%$. On the other hand, Fig. 2 shows the flows estimated with the model corresponding to the \#8 sub-series in a fragment of its period of calibration. As a general conclusion drawn from the visual inspection of each of the adjusted intervals, the model reproduces well most

10 of the patterns of the measured signal, both in magnitude and in time, but overestimates the recession curves associated with flow smaller than $2 \mathrm{~mm} \mathrm{day}^{-1}$, a fact that might be influenced by the OF used in the model, which gives greater weight to larger events. Regarding the interdependence of the parameters, Fig. 3 shows the graph of $P_{1}$ versus $\tau$, obtained with the sub-series \#1 to \#8, which were the only parameters 15 that showed a linear correlation coefficient statistically significant, being its $R^{2}$ equal to 0.839 . However, 8 points are not considered a sufficient sample, and strictly speaking, the sub-intervals involved in the analysis should be entirely independent (with no time overlap).

To evaluate the model, and in consonance with the work of Littlewood (2001), each 20 set of parameters obtained in the calibration was used in the rest of the intervals, giving the coefficients of determination reflected in Table 2 and Fig. 4, covering a range between 0.89 and 0.95 . The average loss with respect to the NS obtained in calibration was $1.1 \%$, with the largest loss being $6.74 \%$, which was produced by applying the best-fit parameters of the sub-period \#7 to interval \#2. Finally, the bottom line of Table 1

25 corresponds to the estimates and coefficients of best fit covering the period 9 May 1980-25 June 1988, which was used by Littlewood in the papers of 2002 and 2003, which the author labelled \#1-6. As can be seen from the table, the logistic model produces a NS of 0.928 . For this sub-period, in the upper panel of Fig. 5, the cumulative distribution functions (CDF) of the observed and estimated flows have been plotted. 
The greatest divergence between both curves occurs in the low-flow region and is in the order of $1.75 \mathrm{~m}^{3} \mathrm{~s}^{-1}$ ( $6 \%$ compared to the average flow).

\section{Comparison with IHACRES in the Teifi Basin}

In 2001, Littlewood applied the IHACRES (PC-IHACRES v1.02) model with 5 param5 eters at a daily scale to this river, in order to give some guidelines on the calibration and validation of parsimonious conceptual models. In order to select the structure that best reflected the observed flow, the author divided the $11 \mathrm{yr}$ he analysed into the 10 intervals already mentioned (rows $3-12$ of Table 1 ).

The best model was considered the one that maximizes the coefficient of determina-

10 tion, with the lowest relative error in the parameters (\%ARPE) of the TF, and being plausible from the hydrological point of view. The author pointed out that when calibrating the subseries \#7, despite the high NS (0.854) and low volume deviation $\left(0.69 \mathrm{~m}^{3} \mathrm{~s}^{-1}\right)$ and \%ARPE (0.03), there was an outlier in the parameter associated with the time of slow flow, concluding in Littlewood (2002) that the module of losses of the IHACRES

5 model did not reproduce low flow very well.

For the 2001 work, the best result was obtained in the \#3 interval with the optimal parameters explaining $88.6 \%$ of the variance with zero volume deviation and \%ARPE of 0.03 . The first 10 pairs of bars of Fig. 6 present, for the sub-periods of calibration, the comparison of the NS achieved with IHACRES, against those obtained with the 3

20 parameter model here proposed. Bars 11 and 12 reflect the lowest and highest value of the coefficient of determination (min Ev TEIFI and Max Ev TEIFI) respectively, calculated from all the simulated intervals. In terms of the NS, the logistic model provided a superior fit, improving with respect to IHACRES a $7.42 \%$ in calibration, $9.29 \%$ in the evaluation, and a $9.1 \%$ considering both. In the 2002 and 2003 papers, Littlewood

25 reduced the overestimation of the low flow from the IHACRES, allowing that the delay parameter was a non-integer and estimating one of the module's losses through trial and error (sub-series \#1-6). With this model with 6 parameters and combining the advantages of manual and automatic calibration (Boyle et al., 2000), he obtained a coeffi9329

cient of determination of 0.884 , with a deviation of $1.11 \mathrm{~m}^{3} \mathrm{~s}^{-1}$ and \%ARPE of 0.0125 . Again, the model based on the logistic equation achieved a NS coefficient greater than the IHACRES model with 6 parameters (see comparison in row 13 of Fig. 6), albeit performing worse in the region of low flows, where the deviation was slightly higher $5\left(1.75 \mathrm{~m}^{3} \mathrm{~s}^{-1}\right)$.

\subsection{River Tywy in Nantgaredig}

The Tywi River Basin is located in Nantgaredig (Wales) and has an area of $1090 \mathrm{~km}^{2}$, with mean annual precipitation and discharge of 1574 and $1107 \mathrm{~mm}$, respectively (Littlewood, 2003). Between 9 May 1980 and 25 June 1988, the average daily flow was $10 \quad 3.26 \mathrm{~mm} \mathrm{day}^{-1}$, being the flows which were exceeded 90 and $10 \%$ of the time 0.39 and $7.84 \mathrm{~mm} \mathrm{day}^{-1}$. As in Teifi, the model based on the logistic equation was applied to the River Tywi over the period corresponding to the sub-series \#1-6 (Littlewood, 2003). The values of the parameters and statistical coefficients achieved are presented in Table 3. They exhibit an overall reasonable fit $(\mathrm{NS}=0.81)$, as well as a null deviation in volume, facts that are supported by the visual analysis of the observed and estimated series. Figure 7, which is a fragment of the calibrated model, reveals that, in general, the model reproduces properly the value and the patterns of behaviour of the observations. However, if we focus on the region of low flows (less than $2.5 \mathrm{~mm} \mathrm{day}^{-1}$ ), it can be appreciated that after dry spells, rainfall events have an immediate response in 20 terms of flow, while the model is unable reflect it (see, for example, the period between April 1984 and October 1984). A possible reason for this is that the intensity of the precipitation exceeds the rate at which the soil can absorb it, regardless of the level of saturation of the basin (hortonian flow). Finally, in the lower panel of Fig. 5, it is shown the CDF of the measured and estimated discharges; the differences between them are 25 small, less than $0.1 \mathrm{~m}^{3} \mathrm{~s}^{-1}$, being the average flow of this river $41.13 \mathrm{~m}^{3} \mathrm{~s}^{-1}$. 


\section{Comparison with IHACRES in the TYWI Basin}

In 2003, Littlewood applied the methodology developed in 2002 to the Tywi Basin using the period corresponding to the sub-series \#1-6. He obtained a NS of 0.805 , a deviation of $2.52 \mathrm{~m}^{3} \mathrm{~s}^{-1}$, \%ARPE of 0.02 and and an almost perfect visual adjustment in

5 the region of low flows. However, as previously mentioned, the method involved substantial manual fitting that is difficult to replicate. Comparing the variance explained by the IHACRES model with 6 parameters with that of the new proposed structure (line 14 of the Fig. 6), both provide very similar results ( 0.810 in the case of the 3 parameter model and 0.805 with the IHACRES).

\section{$10 \quad 4.3$ Coln, Fal and Greta Rivers}

The rivers Coln, Fal and Greta are 3 of the 39 UK basins used in a study that, relying on techniques of regionalization, intended to estimate, in England and Wales, the effect(s) of climate change in the flow regime. The daily application of the IHACRES with 5 parameters to these rivers, with very different characteristics and behaviour, is found

15 in Sefton and Boorman (1997), from which the basic descriptions of the basins have been extracted. The flow regime of Coln River (England), whose basin is $106.7 \mathrm{~km}^{2}$, is dominated by the base flow. Between the 1 October 1980 and the 30 September 1990, there was an average flow of $1.39 \mathrm{~m}^{3} \mathrm{~s}^{-1}$, being the flow that was exceeded the $95 \%$ of the time $0.48 \mathrm{~m}^{3} \mathrm{~s}^{-1}$, and the the mean of the maximum daily flows of every hydro-

20 logical year was $3.43 \mathrm{~m}^{3} \mathrm{~s}^{-1}$. In the River Fal Basin (Cornwall, England), which has an area of $87 \mathrm{~km}^{2}$ and runs through slates and shales, these values were 2.04, 0.39 and $12.08 \mathrm{~m}^{3} \mathrm{~s}^{-1}$, respectively. Finally, the flow rate of the River Greta in Rutherford Bridge (England), which drains an area of $86.1 \mathrm{~km}^{2}$, is dominated by sharp hydrographs, with steep ascending and descending slopes, reaching high flow values in a very short time

25 and quickly descending thereafter to low values; in this basin, the previous hydrological statistics were $2.35,0.11$ and $35.13 \mathrm{~m}^{3} \mathrm{~s}^{-1}$, respectively. The model with 3 parameters based on the Verhulst equation was applied to the periods employed by Sefton and

9331

Boorman in 1997, using from 1986 to 1989 for the calibration and from 1980 to 1990 for the evaluation (always starting and ending in a hydrological year). For each of the basins, Table 4 shows both the parameters and adjustment coefficients obtained, as well as the hydrological statistics calculated from the estimated flows. With regard to 5 the Coln River, it is observed that both the curve of ascent and that of hyperbolic recession generated by the model close reproduce the behaviour of the river (upper panel in Fig. 8), achieving a NS of 0.945 in calibration and of 0.892 in evaluation (Table 4). Regarding the values of the parameters, this basin has the largest $\tau$ of all three with $31.62 \mathrm{~h}$, which can be related to the fact that the flow regime is dominated by the base 10 flow. The rate $A$ was the lowest of the 3 basins, $0.018 \mathrm{~mm}^{-1}$, which corresponds to a slow ascent and descent of the hydrographs. In the basin of the River Fal, the model explained $80.8 \%$ of the variance in the calibration and $82.9 \%$ during the evaluation (Table 4). This river has the smallest $\tau(5.45 \mathrm{~h})$, which is likely linked to a dominance of surface runoff with low retention capacity of the soil. The value of $A$ was greater than in

15 Coln but less than in Greta, with steeper hydrograph than in the first, but softer than in the second. Also in Greta (Fig. 8, middle panel) a noteworthy phenomenon is apparent: the model does not reproduce the small hydrographs, generally in the dry season (for instance in July-August 1988) because it would require a faster response of the basin (greater $A$ ), which is not consistent with the behaviour over the wet periods (dismissing 20 any errors in the rainfall record).

From these graphs, it can be hypothesized that the proposed model is well fitted to simulate runoff production in basins with a single main run-off mechanism (surface, sub-surface or groundwater flow), based on some kind of saturation or memory effect; however, in its present version, it is neither able to reproduce a combination of the 25 aforementioned mechanisms, nor a hortonian flow due to infiltration excess. Some more reflections on this important issue are included in the final discussion of the paper.

Finally, Greta had the lowest determination coefficients of the 3 basins, with NS of 0.743 in calibration and 0.652 in evaluation; with narrow and sharp hydrographs (Fig. 8, lower panel). This river had the highest and lowest flow magnitudes, which 
is ratified both with the given description and with the value of $A$, which is an order of magnitude greater than in Fal. In all cases, the volume deviation was always less than $3.3 \%$ in absolute value (the worst case being the River Fal), which is not very significant. Figure 9 shows, for each of the three rivers, the ECDF of the observed and 5 estimated series during the simulation period (1 October 1980-30 September 1990); discrepancies are moderate and are concentrated in the flow rates below the 50th percentile.

\section{Comparison with IHACRES in the Coln, Fal and Greta River Basins}

With respect to the percentage of variance explained by the IHACRES model during the 10 periods indicated above, in the River Coln it was obtained a $89 \%$ in the calibration and a $85.5 \%$ in the validation; in Fal, for its part, $82 \%$ and $83.7 \%$; finally, in Greta, 68.2 and $61 \%$, respectively. Comparisons between the two models are shown in rows 15 to 20 in Fig. 6. In Coln and Greta, the goodness of fit obtained with the model with 3 parameters were higher than those obtained with the IHACRES, improving the NS coefficient up to

15 a $8.94 \%$. However, in Fal the proposed model performed worse by a $1.4 \%$, which may be due to the coexistence of several runoff generation mechanisms. Finally, regarding the volume deviation from the IHACRES model, it should be noted that, except in Coln, which reached $10 \%$, the others were less than $4 \%$.

\subsection{Influence of different variables of the model}

20 It has been demonstrated that the basic logistic model with 3 parameters proposed in this work, acceptably reproduces the behaviour of the 5 basins in the UK. In order to test the sensitivity of the model to some of the initial hypotheses, some variants of the basic growth model with 3 parameters have been analysed. We have thus examined the influence on the model of considering the factor of memory $\lambda$ as a free parameter, 25 as well as the effect of adopting different values for the ascent and descent rates; finally,

9333

it will also be tested the effect of using other expressions for the equilibrium discharge, different from the one based on Turc-Pike's formula.

\subsubsection{Consideration of the factor of memory $\lambda$ as a free parameter}

As discussed in Sect. 4, the factor of system memory $(\lambda)$, which reflects the weight

5 of the rainfall and evapotranspiration conditions from previous days on the present situation, can be treated as a free parameter, leading to a 4-parameter model. In order to assess whether this can lead to an improvement in the model performance, the variation of the NS against different values of $\lambda$ has been analyzed. The largest deficit in the value of the NS, using a $\lambda$ of 30 days (value chosen by default in the 3-parameter model) and using the optimization algorithm to find the global optimum of the surface, was $2.64 \%$, and occurred in the Tywi Basin (\#1-6), followed by Fal with a $1.7 \%$ and Greta, where that value was $1.46 \%$ (for the calibration period). On the other hand, in both the sub-periods used in Teifi and in Coln, the NS did not increase by more than $1 \%$. Figure 10 shows, in Tywi, Coln, Fal and Greta, the NS variation with $\lambda$. Teifi has not

15 been represented because the impact in this basin was negligible. What was interesting in this basin is that there is a linear correlation of 0.768 between the parameters $A$ and $\lambda$ (Fig. 11); however, as was the case in Fig. 3, in order to make the analysis more rigorous, the sub-sections evaluated should be completely independent, and a larger sample than just 8 points should be considered. In view of these results, in the basins 20 analysed it is not justified to treat $\lambda$ as an additional parameter, since it decreases the model parsimony and increases the risk of equifinality.

\subsubsection{Effect of considering different ascent and descent rates}

We will now check whether the model is improved by introducing a value of $A$ for the ascent $\left(A_{\mathrm{u}}\right)$, different from that of descent $\left(A_{\mathrm{d}}\right)$, which implies estimating 4 parameters: ${ }_{25} P_{1}, \tau, A_{\mathrm{u}}$ and $A_{\mathrm{d}}$. As shown in Fig. 12, with the exception of the Tywi Basin, where 
the NS improved by $5.26 \%$, and in Fal, where it was $3.92 \%$, the improvement was generally less than $1 \%$.

From these results we can deduce similar conclusions as in the previous epigraph, i.e. that the marginal gains in the Tywi and Fal rivers does not justify a new parameter in

5 the model. In any case, this is a preliminary conclusion, and should be checked in more basins and with data with other levels of aggregation (for instance weekly or monthly data).

\subsubsection{Influence of the type of equilibrium discharge function}

One of the cornerstones of the proposed model is the concept of equilibrium discharge. 10 As indicated in Sect. 3, in addition to the expression of Turc-Pike applied in this work, other expressions may be used. Here we will test two more options for the equilibrium discharge function: (1) a constant equilibrium runoff coefficient, yielding:

$Q_{\text {eq }}(t)=P(t) \cdot c_{\text {eq }}$

and (2) another expression, similar to Turc-Pike's, with one degree of freedom (parameter $P_{2}$ ) derived from the equation of Schreiber (1904):

$Q_{\text {eq }}(t)=P(t) \cdot \exp \left(-P_{2} \cdot \Phi^{*}\right)$.

In Fig. 13, the temporal evolution of the equilibrium runoff coefficient, i.e. the ratio between equilibrium discharge and precipitation, is shown for each basin and expression. Thus, although with the variant of the Schreiber function the NS coefficient was im20 proved in 3 of the 5 cases, with a maximum of $1.1 \%$ when compared to the amended Turc-Pike function; the increase gained in this small sample does not possess statistical representativeness. Nevertheless, it is proven that using a constant equilibrium runoff coefficient can result in a loss of up to $50 \%$ in the NS, which indicates that the expression that provides the variability of the equilibriuim coefficient based on the dynamic aridity index is key in the performance of the model.

9335

\section{Discussion}

The equations of growth have been successfully used to reproduce the temporal evolution of aggregate variables from a great variety of systems, in areas such as biology, ecology, sociology, demography, marketing, finance, etc. This article explores the pos-

5 sibility of applying growth equations to model hydrological systems, treating river basins as equivalent or isomorphic to other complex systems at an aggregate level. The basic equation of bounded growth, the logistic or Verhulst equation, has been used for this study, but it is possible to build new models of growth taking into account other structures, many of them already tested in others fields. The growth curve of a basin is

10 roughly equivalent to its "S-Hydrograph", and the Verhulst equation generates a growth curve with its inflection point in the middle of the total carrying capacity. However, the present approach differs from a linear response function, since it solves in a single non-linear equation both the net rainfall and the flow routing.

The key element of the model, in addition to the growth curve, is the notion of an equi15 librium discharge variable over time, which the basin constantly pursues and which is expressed as the product of the instant precipitation and an equilibrium runoff coefficient depending on the prior history of precipitation and evapotranspiration (dynamic aridity index). The flexibilization of Budyko-type formulas based on the aridity index, leaving a free parameter to account for the specific features of a particular basin, as well as the use of an exponential filter to reflect the system memory, also through a single parameter $\lambda$, are working hypotheses with empirical bases that have to be validated. The new model is relatively compact, parsimonious, adaptable and well-conditioned for optimization; in the basins analyzed, the results have been satisfactory, and the phenomenon of equifinality has not been an issue, at least not in a notorious or persistent

25 way. Most of the lumped hydrological models resolve the calculation of the net rainfall and its conversion into flow separately, by introducing all the non-linearity in the first step, and solving the second with a linear transfer function, or the sum of several of them with different decay rates. The logistic model is presented under a single unified 
type, non-linear differential equation, and although in this work it has been applied only to daily data, there are not restrictions in applying it with other time increments. In the IHACRES-type models, the linear transfer function does not have an ascending branch, so that when the $\Delta t$ is lower than the response time of the basin, it is necessary to in-

5 troduce a delay, which must be a multiple of $\Delta t$. In the logistic equation, the ascending branch of the hydrograph is fully implicit in the model, and the delay appears explicitly in the $\tau$ parameter, which may adopt non-integer values. This numerical flexibility hides a more complicated issue: delaying a rainfall record is equivalent to interpolating it to a lower time step, and rainfall series usually show some kind of fractality. In this pa-

10 per, rainfall has been treated as a gentle function that can be linearly interpolated, but a more consistent approach should account for the real noise-like properties of rainfall data; strictly speaking, the proposed model should be addressed as a stochastic differential equation with a delay. Furthermore, if the time step of the available data is similar or larger to the characteristic response time of the basin, here designated as $\tau$, it is

15 not mathematically feasible to estimate it due to the data resolution, and it becomes a tuning parameter (very much dependent on the time step of analysis), rather than a physical variable reflecting an intrinsic property of the basin. This is the case of the five set of data used in this paper.

The logistic model has yielded satisfactory results in the five watersheds analyzed,

20 all different in terms of hydrological behaviour, but with a humid climate as a common factor. It has been also shown that in several basins, the model has failed to generate realistic low-flow discharges, while for medium to high flows (over the $25 \%$ percentile) it has performed remarkably well in all cases. These facts suggest that the logistic model reflects a hydrological response based on a mechanism of excess of saturation, which

25 can be more suitable in basins that receive a significant amount of rain, and possess a certain capacity of infiltration and storage (attributable to any conceptual element working as a reservoir: the canopy, the soil or an aquifer). The logistic equilibrium model seems to be suitable in basins where a dominant storage and saturation mechanism

9337

prevails, and fails to perform so well whenever this principal mechanism is not so clear or changes over the seasons.

The logistic equilibrium model cannot deplete completely the river, i.e. generate a null discharge, which a priori makes it unsuitable for use in ephemeral river basins. Neither 5 can it reproduce runoff from high rainfall intensities and a limited infiltration capacity of the soil: such hortonian mechanism, which is independent from antecedent conditions, would require another set of equations. However, these limitations can be attributed to the logistic model as presented in this paper, but not the whole class of models which can be constructed within the framework of growth laws and the equilibrium discharge concept. Some first trials with other sets of equations in more other watersheds and climates indicate that the general framework of growth models is flexible enough to accommodate several runoff mechanisms. One of the expected contributions of this work is to point at the existence of an alternative conceptual approach based on general equations of growth, which can be useful to address practical hydrological problems,

15 beyond the specific application of the simple logistic equation.

In the basic 3-parameter model presented, a possible dependence between parameters of best fit was detected. In the basin of the River Teifi (Fig. 3), when $P_{1}$ increases in a subseries, so too does the time lag $\tau$; as we have seen, a larger value of $P_{1}$ indicates a greater value of the equilibrium runoff coefficient for the same level of the dynamic

20 aridity index. This dependence may indicate some overlap in the effect of both parameters, creating equifinality, although the statistical representativeness of the available data is low to draw conclusions. Another open issue is the application of growth models with data at different aggregation levels, and the variation of the best-fit parameters with the time step used. This topic is object of ongoing research, but preliminary results 25 indicate that growth models are fairly flexible to adapt to different time steps, albeit with variations of the best-fit parameters.

If, under certain conditions, it can be proved that a hydrologic system is governed by a particular differential equation down to an "infinitesimal scale", for instance the logistic equilibrium equation presented in this work, it becomes easier to investigate 
relationships between the hydrological parameters, the descriptors of the basin, and certain statistical descriptors of the climate, especially the downscaling properties of the rainfall. The ultimate goal is to obtain a tensor-like characterization of hydrological systems, independent from the level of aggregation of the input data. This achieve-

5 ment would open new possibilities of regionalization and classification of river basins, perhaps more robust and consistent than the ones proposed to date.

\section{Conclusions}

The potential of application of general equations of growth for rainfall-runoff transformation has been tested in five wet basins from the UK, previously studied by other authors.

10 In particular, a basic model with 3 parameters has been presented, based on the logistic equation originally proposed by Verhulst and two complementary concepts: the equilibrium discharge function and a dynamic aridity index. The new model differs from other existing lumped models in several aspects: (1) it has fewer parameters, (2) can be solved using an exact numerical scheme, (3) is compact, in the sense that solves

15 the hydrological process in one single step, (4) is intrinsically nonlinear and (5) creates non-exponential recession curves. The basic model yields satisfactory results in all the basins, and the improvement achieved by incorporating an additional parameter (from 3 to 4) has been generally low. To contextualise the model performance, the results have been compared with those from the IHACRES (5-6 parameters), a well-known

20 lumped model that has been previously applied in these basins. In 4 of the 5 cases, the performance of the new model was clearly superior to that of the IHACRES model. In the River Fal, where the results were slightly worse, the model was also competent, as the differences were small in both the calibration and validation; in terms of volume measurement, the deviations obtained with both models were similar. The lo-

25 gistic model performs generally better in high flows than in low flows, especially in Teifi, Tywi and Fal, and it has difficulty in generating peaked hydrographs from a low initial discharge. Another topic for consideration is the interdependence of the parameters: in

9339

the River Teifi it has been observed that there is a relationship between $P_{1}$ and $\tau$, which must be verified with a larger database. Based on these results, it can be affirmed that growth equations, combined with the equilibrium discharge concept, can potentially be an efficient and practical tool for hydrological modelling in certain types of basins.

5 Acknowledgements. The authors would like to show their most profound gratitude to Keith Beven, Thorsten Wagener, Barry Croke and lan Littlewood, for their unwavering, unconditional support and availability during the production of this work.

\section{References}

Andrews, F. T., Croke, B. F. W., and Jakeman, A. J.: An open software environment for hydrological model assessment and development, Environ. Modell. Softw., 26, 1171-1185, 2011.

Arora, V. K.: The use of the aridity index to assess climate change effect on annual runoff, J. Hydrol., 265, 164-177, 2002.

Bai, Y., Wagener, T., and Reed, P.: A top-down framework for watershed model evaluation and selection under uncertainty, Environ. Modell. Softw., 24, 901-916, 2009.

15 Bertalanffy, V.: Quantitative laws in metabolism and growth, Q. Rev. Biol., 32, 217-231, 1957.

Beven, K. J.: Towards a coherent philosophy for modeling the environment, P. Roy. Soc. Lond. A, 458, 2465-2484, 2002.

Beven, K. J.: Rainfall-runoff modelling: the primer, Wiley-Blackwell, Chichester, 2012a.

Beven, K. J.: Causal models as multiple working hypotheses about environmental processes, Comptes Rendus Geoscience, 344, 77-88, 2012b.

Blumberg, A.: Logistic growth rate functions, J. Theor. Biol., 21, 42-44, 1968.

Boyle, D. P., Gupta, H. V., and Sorooshian, S.: Toward improved calibration of hydrologic models: combining the strengths of manual and automatic methods, Water Resour. Res., 36, 3663-3674, 2000.

25 Budyko, M. I.: Evaporation Under Natural Conditions, Gidrometeorizdat, Leningrad, English translation by IPST, Jerusalem, 1948.

Buis, R.: On the generalization of the logistic law of growth, Acta Biotheor., 39, 185-195, 1991.

Carrillo, M. and Gonzalez, J. M.: A new approach to modeling sigmoidal curves, Technol. Forecast. Soc., 69, 233-291, 2002. 
Chow, V. T., Maidment, D. R., and Mays, L. W.: Applied Hydrology, McGraw-Hill, New York, 1988.

Croke, B. F. W.: A technique for deriving an average event unit hydrograph from streamflowonly data for ephemeral quick-flow-dominant catchments, Adv. Water Resour., 29, 493-502, 2006.

Croke, B. F. W. and Jakeman, A. J.: A catchment moisture deficit module for the IHACRES rainfall-runoff model, Environ. Modell. Softw., 19, 1-5, 2004.

Croke, B. F. W. and Jakeman, A. J.: Corrigendum to "A Catchment Moisture Deficit module for the IHACRES rainfall-runoff model", Environ. Model. Softw., 19, (2004) 1-5, Environ. Modell. Softw., 20, doi:10.1016/j.envsoft.2003.09.001, 2005.

Croke, B. F. W. and Littlewood, I. G.: Comparison of alternative loss modules in the IHACRES model: an application to 7 catchments in Wales, MODSIM 2005 International Congress on Modelling and Simulation, edited by: Zerger, A. and Argent, R. M., Modelling and Simulation Society of Australia and New Zealand, Melbourne, 2904-2910, 2005.

15 Duan, Q., Sorooshian, S., and Gupta, V.: Effective and efficient global optimization for conceptual rainfall-runoff models, Water Resour. Res., 28, 1015-1031, 1992.

Evans, J. P. and Jakeman, A. J.: Development of a simple, catchment-scale, rainfallevapotranspiration-runoff model, Environ. Modell. Softw., 13, 385-393, 1998.

Fisher, J. C. and Pry, R. H.: A simple substitution model of technological change, Tech. Fore-

20 casting and Social Change, 3, 75-88, doi:10.1016/S0040-1625(71)80005-7, 1971.

García, A., Sainz, A., Revilla, J. A., Álvarez, C., Juanes, J. A., and Puente, A.: Surface water resources assessment in scarcely gauged basins in the north of Spain, J. Hydrol., 356, 312326, 2008.

Gilpin, M. E., Case, T. J., and Ayala, F. J.: Theta-selection, Math. Biosci., 32, 131-139, 1976.

25 Golec, J. and Sathananthan, S.: Stability analysis of a stochastic logistic model, Math. Comput. Model., 38, 585-593, 2003.

Gupta, H. V., Sorooshian, S., and Yapo, P. O.: Toward improved calibration of hydrologic models: multiple and noncommensurable measures of information, Water Resour. Res., 34, 751-763, 1998.

30 Heinen, M.: Analytical growth equations and their Genstat 5 equivalents, Netherlands, J. Agricult. Sci., 47, 67-89, 1999.

Herron, N. and Croke, B.: Including the influence of groundwater exchanges in a lumped rainfallrunoff model, Math. Comput. Simulat., 79, 2689-2700, 2009.

9341

Jakeman, A. J. and Hornberger, G. M.: How much complexity is warranted in a rainfall-runoff model?, Water Resour. Res., 29, 2637-2649, doi:10.1029/93WR00877, 1993.

Jakeman, A. J., Littlewood, I. G., and Whitehead, P. G.: Computation of the instantaneous unit hydrograph and identifiable component flows with application to two small upland catchments, J. Hydrol., 117, 275-300, 1990.

Jakeman, A. J., Thomas, G. A., and Dietrich, C. R.: System identification and validation for output prediction of a dynamic hydrologic process, J. Forecast., 10, 319-346, 1991.

Jakeman, A. J., Chen, T. H., Post, D. A., Hornberger, G. M., Littlewood, I. G., and Whitehead, P. G.: Assessing uncertainties in hydrological response to climate at large scale, IAHS Publ., $10 \quad 37-47,1993$.

Kokkonen, T. S. and Jakeman, A. J.: A comparison of metric and conceptual approaches in rainfall-runoff modeling and its implications, Water Resour. Res., 37, 2345-2352, 2001.

Kuczera, G. and Mroczkowski, M.: Assessment of hydrologic parameter uncertainty and the worth of multiresponse data, Water Resour. Res., 34, 1481-1489, 1998.

15 Lamb, R.: Calibration of a conceptual rainfall-runoff model for flood frequency estimation by continuous simulation, Water Resour. Res., 35, 3103-3114, doi:10.1029/1999WR900119, 1999.

Littlewood, I. A. N.: Practical aspects of calibrating and selecting unit hydrograph-based models for continuous river flow simulation, Hydrolog Sci. J., 46, 795-811, 2001.

20 Littlewood, I. G.: Improved unit hydrograph characterisation of the daily flow regime (including low flows) for the River Teifi, Wales: towards better rainfall-streamflow models for regionalisation, Hydrol. Earth Syst. Sci., 6, 899-911, doi:10.5194/hess-6-899-2002, 2002.

Littlewood, I. G.: Improved unit hydrograph identification for seven Welsh rivers: implications for estimating continuous streamflow at ungauged sites, Hydrolog. Sci. J., 48, 743-762, 2003.

25 Littlewood, I. G.: United Kingdom hydrometric data, physical catchment descriptors and other hydroclimatological information available via the internet for PUB, available at: http://tdwg. catchment.org/documents/Data60UK.pdf (last access: 13 July 2013), 2006.

Lotka, A. J.: Elements of Physical Biology, Williams \& Wilkins, Baltimore, 1925.

Malthus, R.: An Essay on the Principle of Population, 1st Edn. of 1798, Pickering, London, 1986.

Marchetti, C. and Nakicenovic, N.: The Dynamics of Energy Systems and the Logistic Substitution Model, International Institute for Applied Systems Analysis, Laxenburg, Austria, 1980. 
Moore, R. J.: The PDM rainfall-runoff model, Hydrol. Earth Syst. Sci., 11, 483-499, doi:10.5194/hess-11-483-2007,

Mroczkowski, M., Raper, P. G., and Kuczera, G.: The quest for more powerful validation of conceptual catchment models, Water Resour. Res., 33, 2325-2335, doi:10.1029/97WR01922, 1997.

Ortiz, E.: Memoria-informe sobre modelos de previsión hidrológica empleados en otras organizaciones, Hidrogaia S.L., Dirección General del Agua, 2009.

Perrin, C., Michel, C., and Andréassian, V.: Improvement of a parsimonious model for streamflow simulation, J. Hydrol., 279, 275-289, 2003.

10 Pike, J. G.: The estimation of annual runoff from meteorological data in a tropical climate, J. Hydrol., 2, 116-123, 1964.

Richards, F. J.: A flexible growth function for empirical use, J. Exp. Bot., 10, 290-301, 1959.

Savageau, M. A.: Growth equations: A general equation and a survey of special cases, Math. Biosci., 48, 267-278, 1980.

15 Savenije, H. H. G.: HESS Opinions "The art of hydrology"*, Hydrol. Earth Syst. Sci., 13, 157161, doi:10.5194/hess-13-157-2009, 2009.

Schreiber, P.: Uber die Beziehungen Zwischen dem Niederschlag und der Wasserfuhrung der Flusse in Mitteleuropa, Meteorol. Z., 21, 441-445, 1904.

Sefton, C. E. M. and Boorman, D. B.: A regional investigation of climate change impacts on UK streamflows, J. Hydrol., 195, 26-44, 1997.

Sefton, C. E. M. and Howarth, S. M.: Relationships between dynamic response characteristics and physical descriptors of catchments in England and Wales, J. Hydrol., 211, 1-16, 1998.

Singh, V. P. and Woolhiser, D. A.: Mathematical modeling of watershed hydrology, J. Hydrol. Eng.-ASCE, 7, 270-292, doi:10.1061/(ASCE)1084-0699(2002)7:4(270), 2002.

25 Sivapalan, M., Takeuchi, K., Franks, S. W., Gupta, V. K., Karambiri, H., Lakshmi, V. Liang, X., McDonnell, J. J., Mendiondo, E. M., O'Connell, P. E., Oki, T., Pomwroy, J. W., Schertzer, D., Uhlenbrook, S., and Zehe, E.: IAHS decade on Predictions in Ungauged Basins (PUB) 20032012: Shaping an exciting future for the hydrological sciences, Hydrolog. Sci. J., 48, 857880, 2003.

30 Smith, F. E.: Population dynamics in Daphnia Magna and a new model for population growth, Ecology, 44, 651-663, 1963.

Smith, H. and Waltman, P.: The Mathematical Theory of Chemostats, Cambridge University Press, 1997.

9343

Todini, E.: Hydrological catchment modelling: past, present and future, Hydrol. Earth Syst. Sci., 11, 468-482, doi:10.5194/hess-11-468-2007, 2007.

Törn, A. A.: A program for global optimization, multistart with clustering (MSC), in: Proceedings of Euro IFIP 79, North-Holland, Amsterdan, edited by: Samet, P. A., 427-434, 1979.

5 Tsoularis, A. and Wallace, J.: Analysis of logistic growth models, Math. Biosci., 179, 21-55, 2002.

Turner, J. M. E., Bradley, J. E. L., Kirk, K. A., and Pruitt, K. M.: A theory of growth, Math. Biosci., 29, 367-373, 1976.

Verhulst, P. F.: Notice sur la loi que la population suit dans son accroissement, Correspondance

$10 \quad$ Mathematique et Physique Publiee par A, Quetelet, 10, 113-121, 1838.

Wagener, T. and Montanari, A.: Convergence of approaches toward reducing uncertainty in predictions in ungauged basins, Water Resour. Res., 47, W06301, doi:10.1029/2010WR009469, 2011.

Wagener, T., Wheater, H. S., and Gupta, H. V.: Rainfall-runoff modelling in gauged and ungauged catchments, Imperial College Press, London, UK, 332 pp., 2004.

Wheater, H. S., Jakeman, A. J., and Beven, K. J.: Progress and directions in rainfall-runoff modelling, in: Modelling Changes in Environmental Systems, edited by: Jakeman, A. J., Beck, M. B., and McAleer, M. J., John Wiley \& Sons, Chichester, 101-132, 1993.

Wittenberg, H.: Nonlinear analysis of flow recession curves, IAHS Publ., 221, 61-68, 1994.

20 Wittenberg, H. and Sivapalan, M.: Watershed groundwater balance estimation using streamflow recession analysis and baseflow separation, J. Hydrol., 219, 20-33, 1999.

Yapo, P. O., Gupta, H. V., and Sooroshian, S.: Automatic calibration of conceptual rainfall-runoff models: sensitivity to calibration data, J. Hydrol., 181, 23-48, 1996.

Yapo, P. O., Gupta, H. V., and Sorooshian, S.: Multi-objective global optimization for hydrologic models, J. Hydrol., 204, 83-97, 1998.

Ye, W., Bates, B. C., Viney, N. R., Sivapalan, M., and Jakeman, J.: Performance of conceptual rainfall-runoff models in low-yielding ephemeral catchments, Water Resour. Res., 33, 153166, 1997.

Young, P. C.: Recursive Estimation and Time-Series Analysis, an Introduction for the Student

$30 \quad$ and Practicioner, 2nd Edn., Springer, 2011.

Zeide, B.: Analysis of growth equations, Forest Sci., 39, 594-616, 1993. 
Table 1. Calibration of the model in the Teifi River Basin. Intervals corresponding to the subseries used by Littlewood in 2001, 2002 and 2003.

\begin{tabular}{|c|c|c|c|c|c|c|}
\hline \multicolumn{3}{|c|}{ Subperiods } & \multicolumn{3}{|c|}{ Parameters } & \multirow{2}{*}{ NS daily } \\
\hline & Start day & End day & $P_{1}$ & $\tau(\mathrm{h})$ & $A\left(\mathrm{~mm}^{-1}\right)$ & \\
\hline$\# 1$ & 9 May 1980 & 11 Aug 1983 & 1.233 & 14.579 & 0.05 & 0.919 \\
\hline \#2 & 12 Aug 1981 & 6 Jul 1984 & 1.251 & 13.798 & 0.054 & 0.905 \\
\hline \#3 & 18 Jul 1982 & 1 Jun 1985 & 1.079 & 14.316 & 0.057 & 0.937 \\
\hline \#4 & 12 Aug 1983 & $21 \mathrm{Jul} 1986$ & 1.211 & 12.471 & 0.056 & 0.931 \\
\hline \#5 & 17 Jul 1984 & 30 Aug 1987 & 1.321 & 14.567 & 0.059 & 0.924 \\
\hline$\# 6$ & 2 Jun 1985 & 25 Jun 1988 & 1.463 & 15.943 & 0.059 & 0.945 \\
\hline \#7 & 22 Jul 1986 & 9 Aug 1989 & 1.684 & 16.543 & 0.058 & 0.950 \\
\hline \#8 & 31 Aug 1987 & 14 Aug 1990 & 1.626 & 16.57 & 0.052 & 0.954 \\
\hline$\# 1-8$ & 9 May 1980 & 14 Aug 1990 & 1.342 & 15.161 & 0.054 & 0.932 \\
\hline$\# X$ & 18 Jul 1982 & 11 Aug 1983 & 1.029 & 15.725 & 0.06 & 0.936 \\
\hline \multicolumn{3}{|c|}{ Mean \#1-\#8 } & 1.359 & 14.848 & 0.056 & 0.933 \\
\hline \multicolumn{3}{|c|}{ \#1-6 (9 May 1980-25 Jun 1988) } & 1.289 & 15.2 & 0.055 & 0.928 \\
\hline
\end{tabular}

9345

Table 2. River Teifi. Evaluation of the proposed model. Application of best-fit parameters obtained in each interval (main diagonal) to the rest of sub-periods. Example: in row 1, the best-fit parameters obtained with the sub-series \#1 have been applied to the \#2, \#3, \#4, \#5, \#6, \#7, \#8, $\# 1-8$ and $\# X$.

\begin{tabular}{lcccccccccc}
\hline & & & & \multicolumn{3}{c}{ NS daily } & & & & \\
& $\# 1$ & $\# 2$ & $\# 3$ & $\# 4$ & $\# 5$ & $\# 6$ & $\# 7$ & $\# 8$ & $\# 1-8$ & $\# x$ \\
\hline$\# 1$ & 0.919 & 0.903 & 0.938 & 0.926 & 0.911 & 0.922 & 0.916 & 0.940 & 0.926 & 0.940 \\
$\# 2$ & 0.917 & 0.905 & 0.938 & 0.931 & 0.918 & 0.929 & 0.924 & 0.943 & 0.929 & 0.940 \\
$\# 3$ & 0.909 & 0.896 & 0.937 & 0.924 & 0.907 & 0.917 & 0.910 & 0.933 & 0.920 & 0.938 \\
$\# 4$ & 0.912 & 0.903 & 0.937 & 0.931 & 0.916 & 0.925 & 0.919 & 0.937 & 0.924 & 0.938 \\
$\# 5$ & 0.912 & 0.903 & 0.930 & 0.926 & 0.924 & 0.939 & 0.936 & 0.947 & 0.929 & 0.934 \\
$\# 6$ & 0.908 & 0.897 & 0.917 & 0.915 & 0.924 & 0.945 & 0.945 & 0.950 & 0.928 & 0.924 \\
$\# 7$ & 0.898 & 0.886 & 0.896 & 0.896 & 0.918 & 0.946 & 0.950 & 0.950 & 0.922 & 0.904 \\
$\# 8$ & 0.913 & 0.900 & 0.916 & 0.912 & 0.921 & 0.944 & 0.946 & 0.954 & 0.930 & 0.923 \\
$\# 1-8$ & 0.918 & 0.906 & 0.935 & 0.928 & 0.923 & 0.937 & 0.934 & 0.949 & 0.932 & 0.939 \\
$\# X$ & 0.904 & 0.890 & 0.934 & 0.917 & 0.903 & 0.914 & 0.908 & 0.932 & 0.916 & 0.936 \\
\hline
\end{tabular}


Table 3. Tywi River. Interval corresponding to the sub-series used by Littlewood in 2002 and 2003.

\begin{tabular}{ccccccc}
\hline & \multicolumn{2}{c}{ Subperiods } & \multicolumn{3}{c}{ Parameters } & NS daily \\
& Start day & End day & $P_{1}$ & $\tau(\mathrm{h})$ & $A\left(\mathrm{~m} \mathrm{~m}^{-1}\right)$ & \\
\hline$\# 1-6$ & 9 May 1980 & 25 Jun 1988 & 0.556 & 14.391 & 0.055 & 0.81 \\
\hline
\end{tabular}

Table 4. Rivers Coln, Fal y Greta. Parameters and goodness of fit in calibration (1 Ocotber 1986-30 September 1989) and simulation periods (1 Ocotber 1980-30 September 1990). Note: Hydrological statistics are: (1) Average flow $\left(\mathrm{m}^{3} \mathrm{~s}^{-1}\right)$. (2) The flow that was exceeded the $95 \%\left(\mathrm{~m}^{3} \mathrm{~s}^{-1}\right)$. (3) The mean of the maximum daily flows of every hydrological year $\left(\mathrm{m}^{3} \mathrm{~s}^{-1}\right)$.

\begin{tabular}{lrrrrlllllrr}
\hline & \multicolumn{3}{c}{ Parameters } & \multicolumn{2}{c}{ Calibration } & \multicolumn{4}{c}{ Simulation } \\
& $P_{1}$ & $\tau(\mathrm{h})$ & $A\left(\mathrm{~mm}^{-1}\right)$ & NS daily & R.Bias (\%) & NS daily & R.Bias (\%) & $\begin{array}{c}\text { Hydrological statistics } \\
(1)\end{array}$ & & $(2)$ & $(3)$ \\
\hline Coln & 1.101 & 31.618 & 0.018 & 0.945 & -0.139 & 0.892 & -1.186 & 1.375 & 0.498 & 3.970 \\
Fal & 0.734 & 5.454 & 0.036 & 0.808 & -3.3 & 0.829 & -0.1 & 1.97 & 0.318 & 11.137 \\
Greta & 0.936 & 8.786 & 0.325 & 0.743 & 0 & 0.652 & 1.950 & 2.301 & 0.126 & 27.299 \\
\hline
\end{tabular}



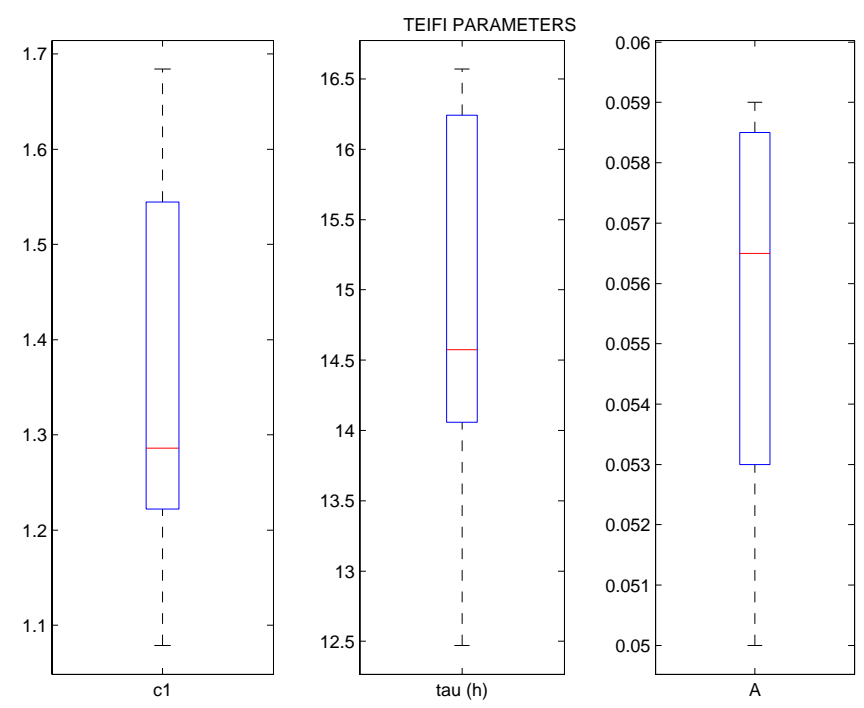

Fig. 1. Box-whisker plots of the parameters obtained in periods \# 1, \#2, \#3, \#4, \#5, \#6, \#7 and \#8 for the Teifi River Basin.

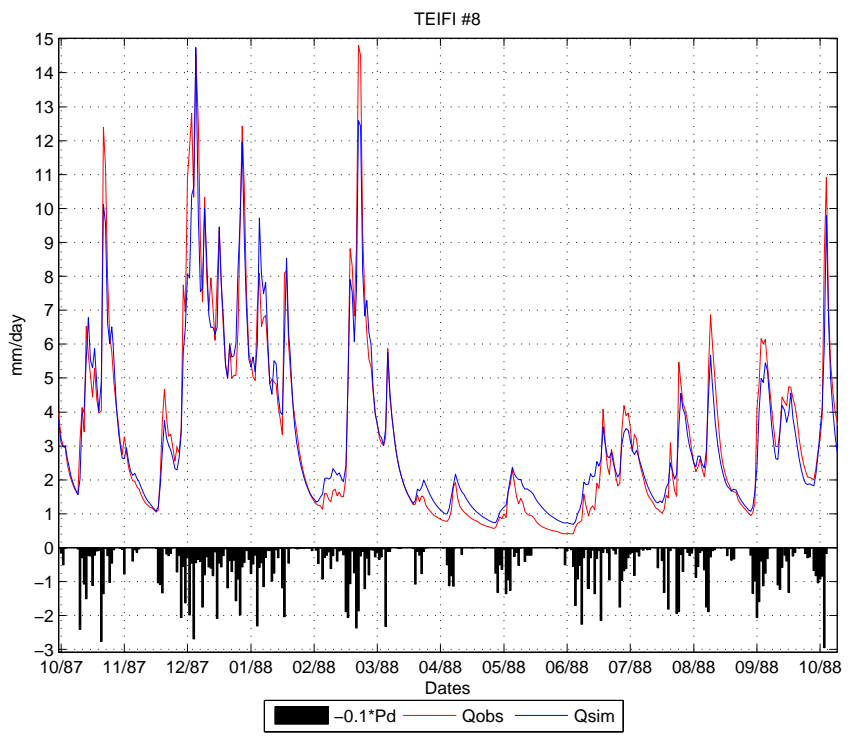

Fig. 2. Observed flows, estimated flows and -0.1 . daily precipitation in a fragment of the subseries \#8. Teifi River Basin. 


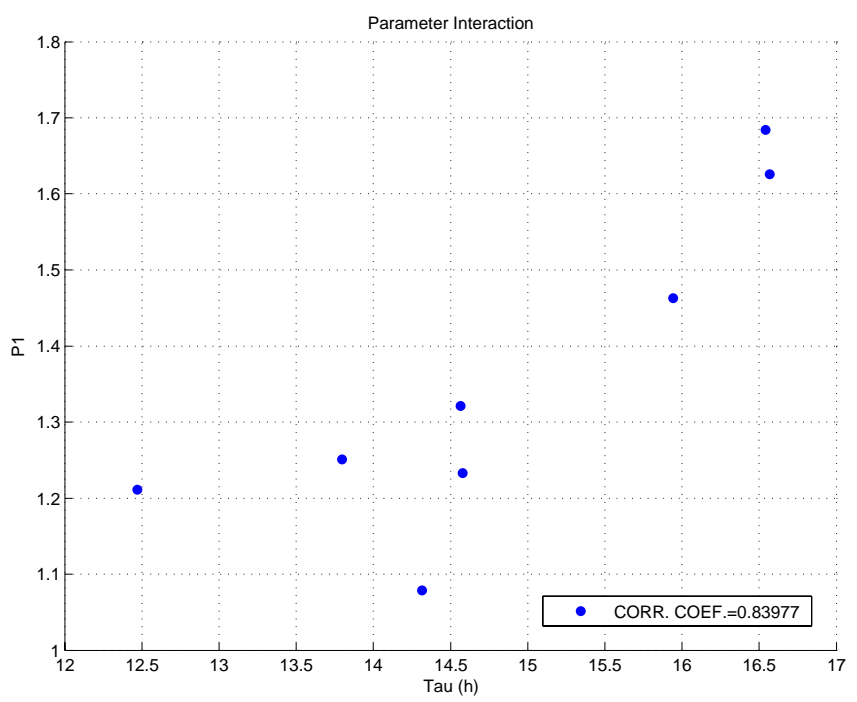

Fig. 3. Intercorrelation of parameters $P_{1}$ and $\tau$. Sub-series \#1, \#2, \#3, \#4, \#5, \#6, \#7 and \#8. Teifi River Basin.

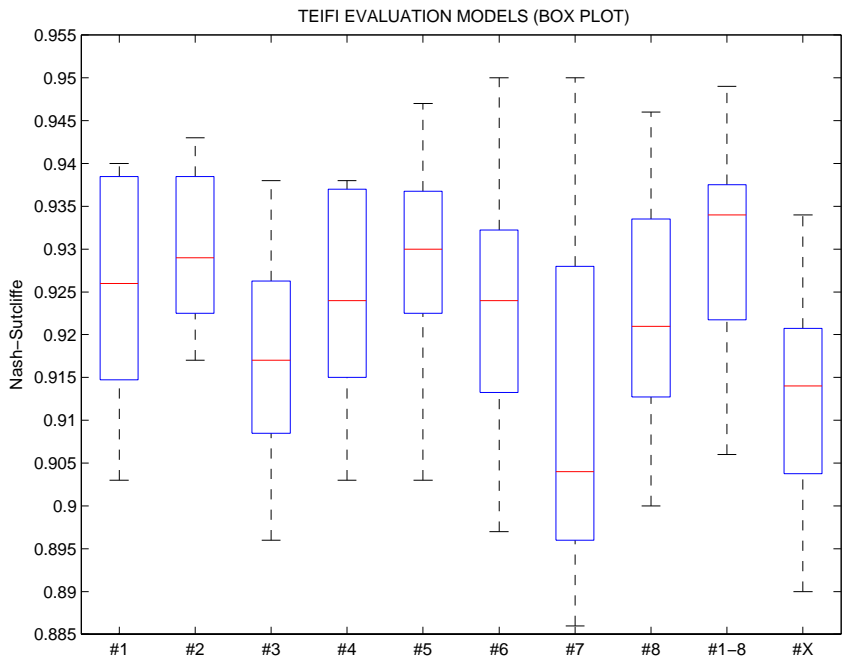

Fig. 4. Evaluation of each calibration sub-period in the remaining sub-periods (excluding itself). Teifi River Basin. 

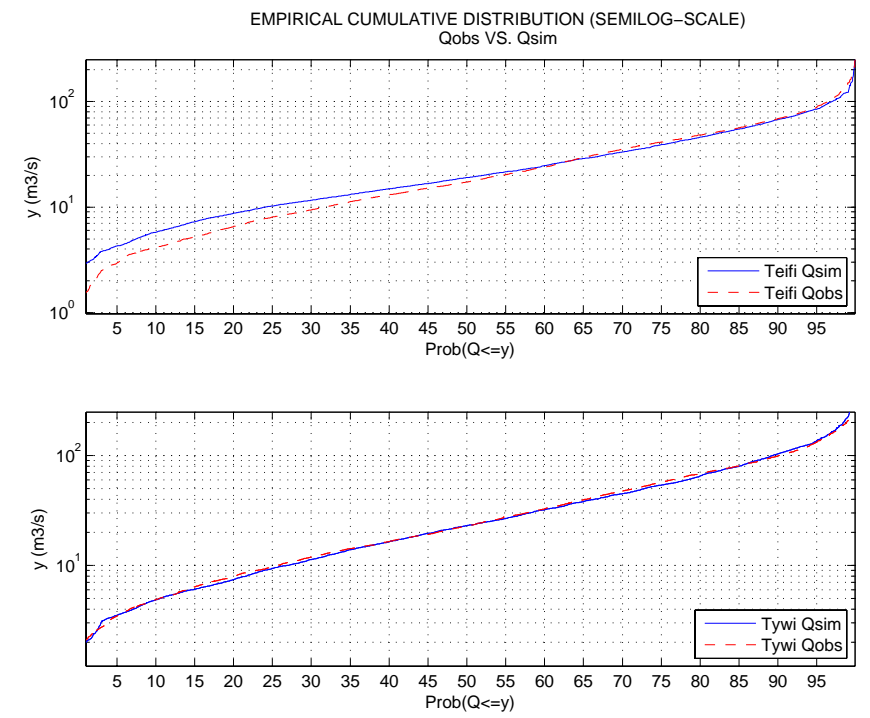

Fig. 5. ECDF (Empirical cumulative distribution function) of the observed and estimated flows. Rivers Teifi (upper panel) and Tywi (lower panel).

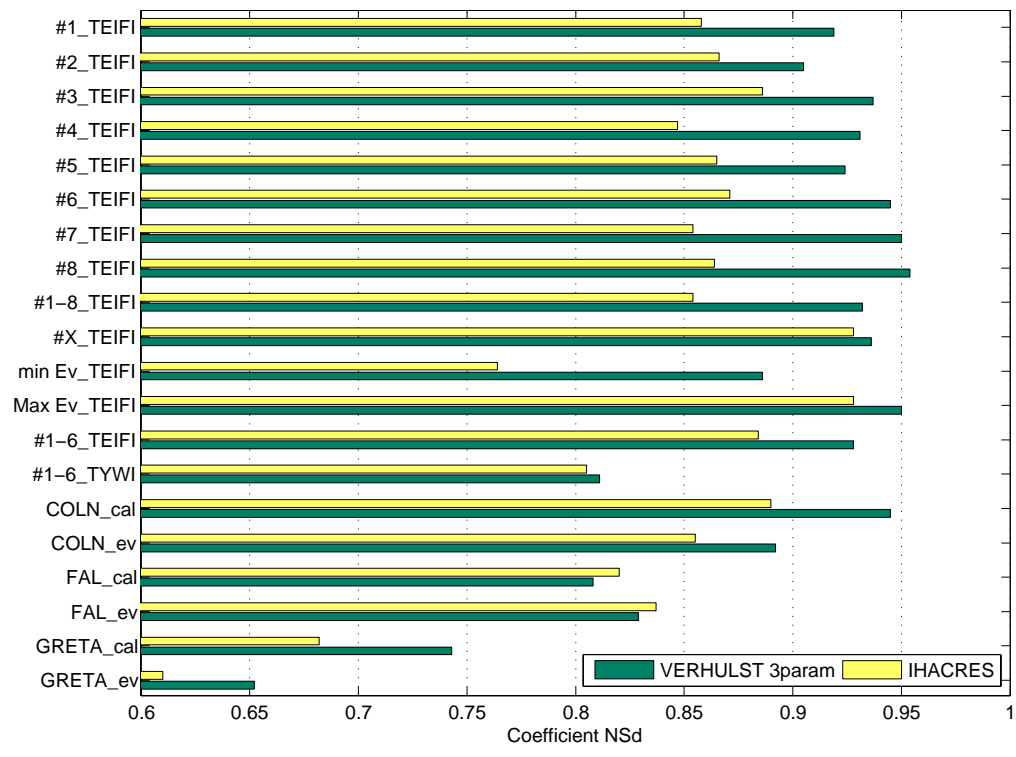

Fig. 6. NS coefficients of the logistic (Verhulst) model with 3 parameters vs. the IHACRES model. 


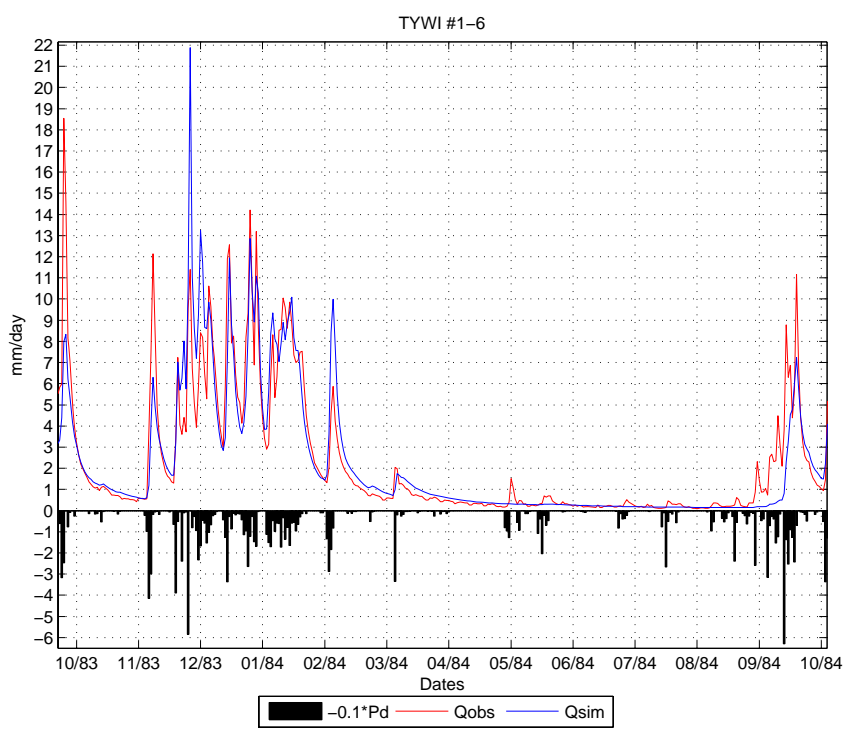

Fig. 7. Observed flows, estimated flows and -0.1 . daily precipitation in a fragment of the subseries \#1-6. Tywi River Basin.
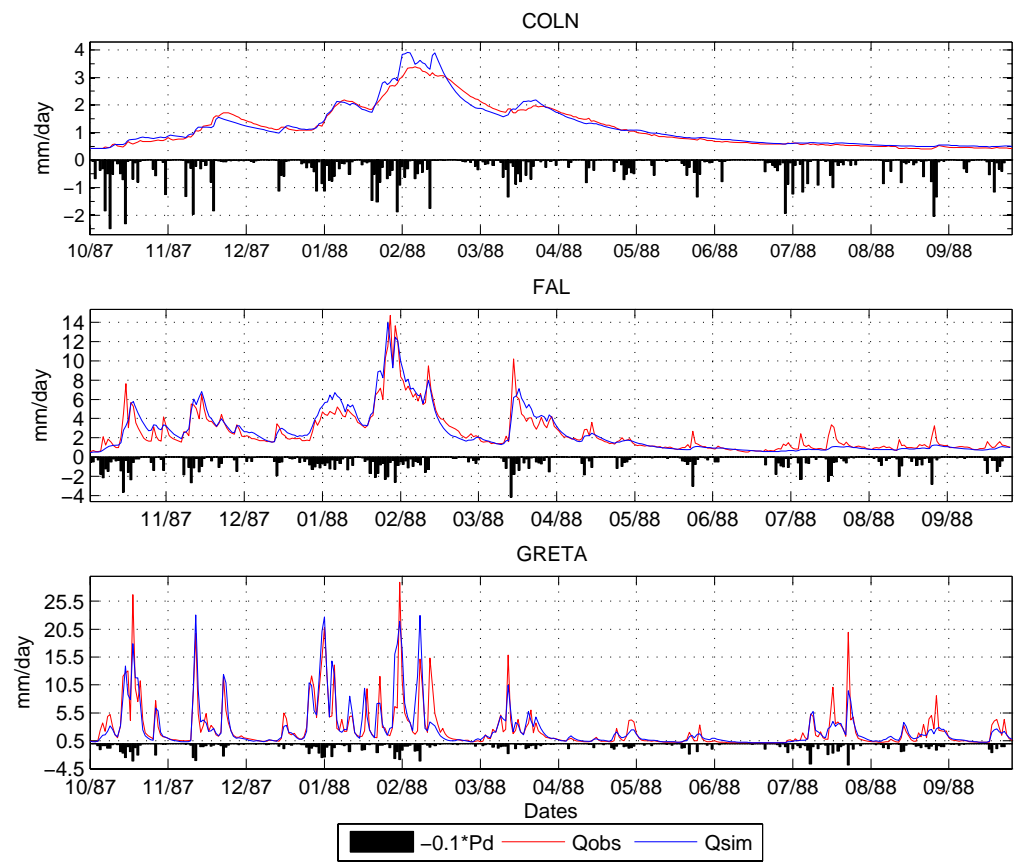

Fig. 8. Observed flows, estimated flows and -0.1 . daily precipitation in the period October 1987-October 1988. Rivers Coln, Fal and Greta. 



Fig. 9. ECDF (empirical cumulative distribution function) of the observed and estimated flows from 1 October 1980 to 30 September 1990. Rivers Coln, Fal and Greta (upper, middle and lower panels, respectively).
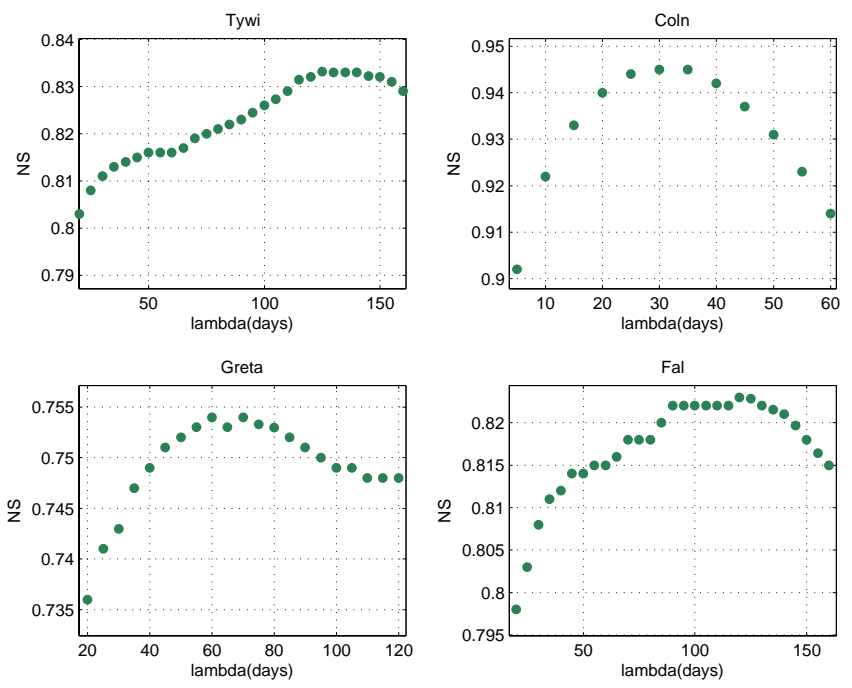

Fig. 10. Influence of parameter $\lambda$ on the NS coefficient. Rivers Tywi, Coln, Greta and Fal. 


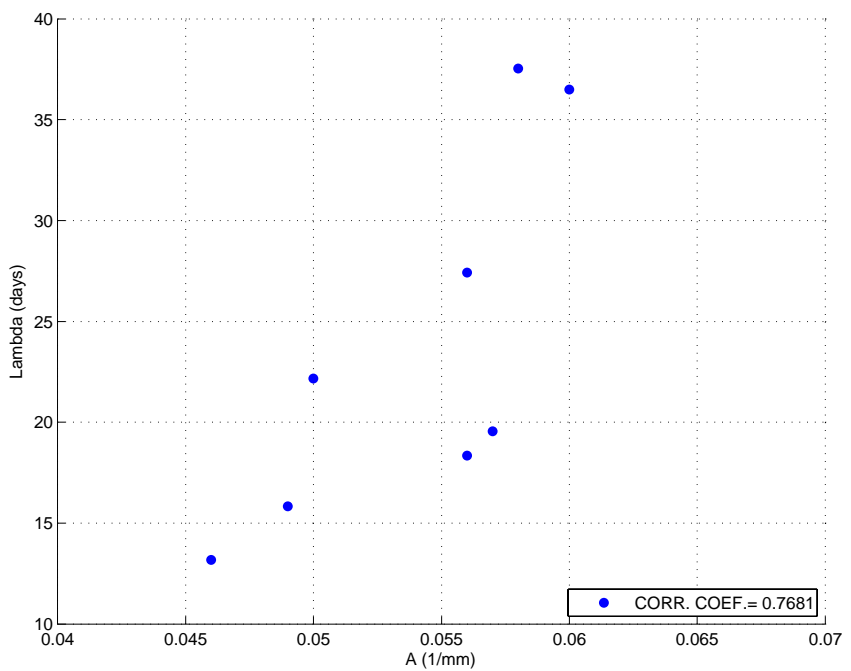

Fig. 11. Correlation between best-fit parameters $\lambda$ and $A$ obtained for sub-periods \#1, 2, 3, 4, 5, 6, 7 and 8 in the River Teifi.

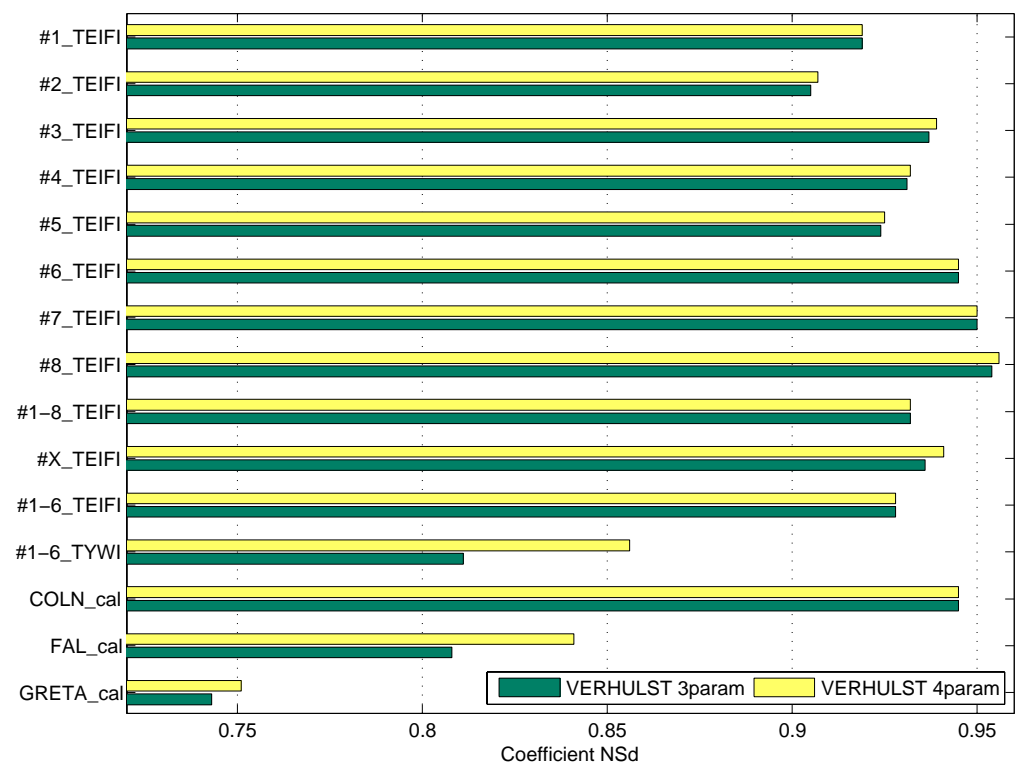

Fig. 12. NS coefficient of the logistic (Verhulst) model with 3 parameters $\left(P_{1}, \tau, A\right)$ vs. the same model with 4 parameters $\left(P_{1}, \tau, A_{\mathrm{u}}, A_{\mathrm{d}}\right)$. 
TEIFI \#1-6

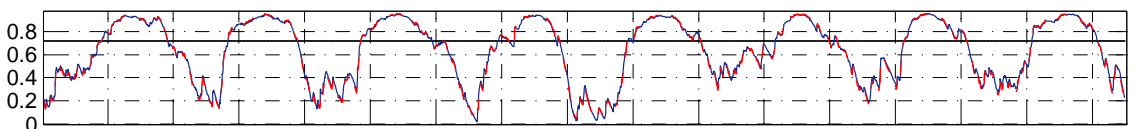

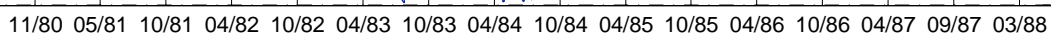
TYWI \#1-6

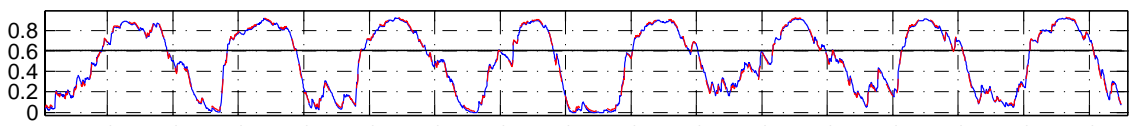

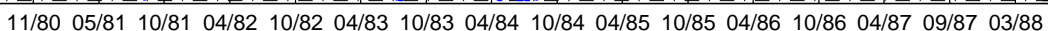
COLN calib
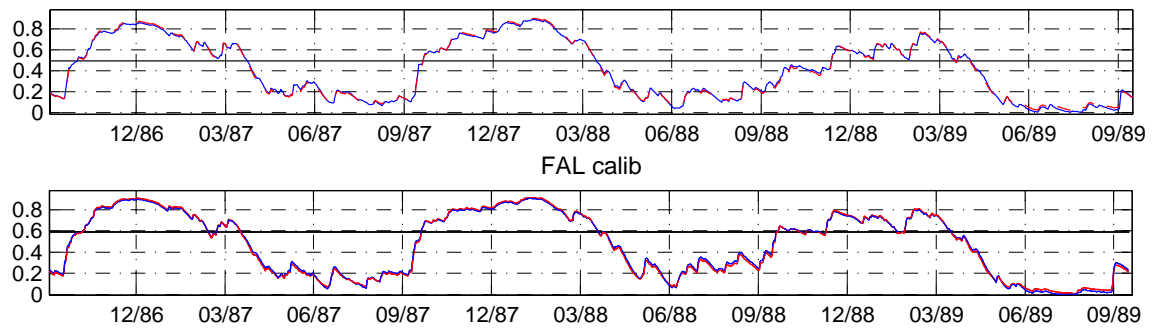
GRETA calib

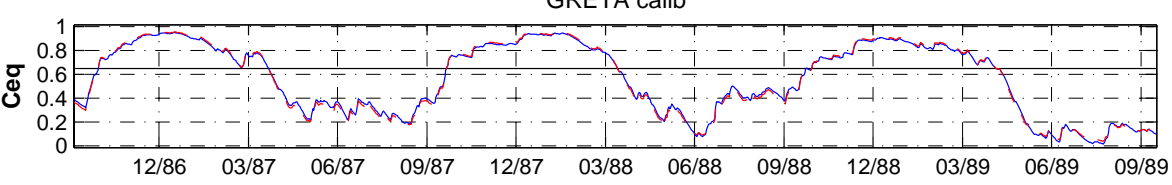
DATE (days)

$$
\text { Constant } \longrightarrow \text { Schreiber }--- \text { Turc Pike }
$$

Fig. 13. Influence of three equilibrium discharge expressions (constant, Schreiber and TurcPike) in terms of evolution of the equilibrium runoff coefficient $\left(c_{\text {eq }}\right)$ for each basin. 